\title{
New polymer-based treatments for the prevention of damage by salt crystallization in stone
}

\author{
Serena Andreotti • Elisa Franzoni (1D) Encarnacion Ruiz-Agudo • \\ George W. Scherer • Paola Fabbri $\cdot$ Enrico Sassoni $\cdot$ Carlos Rodriguez-Navarro
}

Received: 11 December 2018/Accepted: 26 December 2018/Published online: 31 January 2019

(C) The Author(s) 2019

\begin{abstract}
Salt crystallization can produce severe damage in porous stones, with a dramatic impact on cultural heritage conservation. Such damage is related to the fact that repulsive forces arise between the salt crystals and the pore wall, generating a disjoining pressure that frequently exceeds the tensile strength of stone. In this paper, new treatments are proposed, aimed at preventing salt damage by depositing a thin layer of polymeric coatings over the stone's pore surfaces. These coating are expected to change the surface chemistry, eliminating the repulsion between
\end{abstract}

Electronic supplementary material The online version of this article (https://doi.org/10.1617/s11527-018-1309-6) contains supplementary material, which is available to authorized users.

S. Andreotti · E. Franzoni $(\varangle) \cdot$ P. Fabbri · E. Sassoni Department of Civil, Chemical, Environmental and Materials Engineering (DICAM), University of Bologna, Bologna, Italy

e-mail: elisa.franzoni@unibo.it

E. Ruiz-Agudo $\cdot$ C. Rodriguez-Navarro

Department of Mineralogy and Petrology, University of Granada, Granada, Spain

G. W. Scherer

Department of Civil and Environmental Engineering

(CEE), Princeton University, Princeton, USA

\section{E. Franzoni}

Centre for Applied Research on Buildings and Construction (CIRI-EC), University of Bologna, Bologna, Italy the growing crystals and the pore wall and hence the development of the disjoining pressure. Several biopolymers were tested on these substrates: silica glass, calcite, and calcite subjected to a pre-treatment with diammonium hydrogen phosphate (DAP), aimed at preventing calcite dissolution and acting as an anchoring substrate for the polymer coating. Selected polymer treatments were applied to porous Globigerina limestone samples, which were subjected to crystallization tests with sodium sulfate, obtaining promising results (i.e., significant reduction in stone damage), especially when the polymers were applied after the DAP treatment.

Keywords Salt damage $\cdot$ Sodium sulfate . Disjoining pressure $\cdot$ Hydroxyapatite $\cdot$ Calcite dissolution · Biopolymers - Salt crystallization test

\section{Introduction}

The stress induced by salt crystallization inside porous materials of historical buildings, such as stone, brick and mortar, is one of the most widespread cause of damage in architectural heritage [1-5]. This stress may frequently exceed the tensile strength of building materials, which is usually quite low, and cause crack formation and propagation, resulting in severe damage that deteriorates both structural and decorative elements [6]. 
Salts may come from capillary water absorption from the soil (i.e., rising damp). In this case, the wall surface is wet up to the height at which the rate of water supply falls below the evaporation rate [1]. Above this height the evaporation front moves deeper inside the wall, where the saline solution can reach supersaturation and salts will precipitate inside the pore network, forming potentially disruptive subflorescence [6]. Even in the absence of continuous supply by rising damp, building materials may contain salts (leached from mortar joints or created by interaction with pollutants), which may be subjected to crystallization cycles, due to their deliquescence under fluctuating relative humidity [2]. Salt crystallization can also be caused by cooling, due to the strong temperature dependence of the solubility of some salt phases [7].

The damage mechanism related to salts has been widely investigated, and a review on crystallization in porous materials is provided in $[6,8-10]$. The existence of crystallization pressure directly suggests a strong repulsion between the growing crystal and the opposing surface [6]. Indeed, most salt crystals seem to repel most stone minerals [10]. This repulsion between stone and salt crystal, which can be attributed to Van der Waals forces in the particular case of ice, is possibly related for other crystals to electrostatic and solvation forces, acting across the liquid film present between the salt and the pore wall. Indeed, the two surfaces (salt and pore wall) will organize the orientation of adjacent water molecules and ions to minimize the energy of each surface; thus, repulsion between the two differently organized layers will arise as they approach one another. If the peak disjoining pressure arising between the crystal and the pore wall is smaller than the tensile strength of stone, the salt can come into contact with the mineral without causing damage. However, in the more typical case where the peak disjoining pressure is higher than the tensile strength, the stone will fail before the salt touches the pore walls. The damage due to crystallization will depend on the degree of supersaturation reached, which is influenced by transport processes, the type of salt, the salt distribution in the pore, and the pore size distribution [8]. Salt damage may be also associated with other kinds of weathering, such as the dissolution of calcite in carbonate stone [9].

To mitigate the damage by salts, various strategies have been proposed. Of course, the control of environmental conditions (temperature and relative humidity) and the elimination of the water source (rising damp, rain absorption) will help towards this aim. However, efficient environmental control is only possible indoors, whereas a complete elimination of rising damp is seldom possible [11] and the use of hydrophobic agents to prevent the access of humidity (e.g., rain) to porous stone may even exacerbate salt damage if some moisture is present below the waterrepellent layer [1].

Many studies focused on the use of crystallization inhibitors, promoters and modifiers that, once introduced into the salt contaminated material, control the crystallization of salts [12-19], avoiding dissolution and precipitation cycles [20] and/or fostering the crystallization of salts on the stone surface as harmless efflorescence, thereby precluding their deleterious inpore crystallization. The well-known scale inhibitors (such as polyphosphate, phosphate, carboxylates, polyacrylic acid derivates, benzotriazoles) used industrially are typical examples of crystallization inhibitors or habit modifiers [13].

A different strategy to mitigate the damage caused by salt crystallization to stone of cultural heritage was proposed in [1, 21, 22] and it is based on the elimination of the disjoining pressure acting between the growing crystal and the pore wall, through the deposition of a polymeric coating on the pore surface [1]. The idea is that no pressure will be exerted on the stone if the growing salt crystals are able to touch the treated pore wall instead of repelling it (the scenario of salt crystal growth in the presence of a polymer coating having a low contact angle with the salt is illustrated in Figure S1-1 of Supplementary material).

Some polymers were tested for this purpose in $[21,22]$, and their ability to prevent damage by salt crystallization in Indiana limestone was investigated, yielding some promising results. However, a systematic and detailed investigation has not been performed yet. In particular, calcite dissolution, occurring in small defects of the polymer coating or when the coating is not continuous, might cause the progressive detachment of the coating from the pore wall, with a subsequent loss of the treatment effectiveness.

\section{Rationale and aim of the research}

In the present paper, new treatments are tested for stone, aimed at minimizing the disjoining pressure 
acting between the salt crystal and the pore wall, according to the strategy proposed in $[1,21]$. The new treatments are based on environmentally friendly water-based polymer solutions, which are expected to fulfil the following general requirements:

- the polymer molecular structure contains functional moieties acting as anchoring groups towards the mineral surface, and the interaction is strong enough to displace the water adsorbed on the stone surface;

- the polymer has film-forming capability, and it generates a continuous coating that covers the pore surface;

- the salt crystal is chemically attracted by the polymer through its functional moieties, and interaction is stable over time;

- the polymer exhibits highly flexible chains, that allow fast interaction with any ionic crystal approaching the wall by quick change of the molecular conformation, to improve spontaneous segregation of the anchoring functional groups at the outermost surface of the pore. Moreover, high molecular weight should be avoided to prevent osmotic swelling that imposes stress on the stone, which was blamed for the failure of the treatment in a previous study [22];

- the polymer must be not hydrophobic, thereby not altering the water transport properties which may lead merely to an apparent improvement of the resistance to salt weathering, owing to a reduced absorption of saline solution and thus to a lower salt contamination of the treated stone.

For the purpose of this research, bio-based and biodegradable polyelectrolytes were selected, along with a non-bio-based polyelectrolyte that gave some promising results in a previous study [21]. Biodegradable polymers were selected because of their minimal toxicity and compliancy with a new concept of 'reversibility' of the stone treatment discussed in a recent paper [23]. In fact, the introduction of several polymeric treatments inside heritage stone elements over the last decades caused severe problems, due to the presence of aged and no longer effective residues in the stone, that are hard or impossible to remove and also jeopardize the applicability of further new treatments. For this reason, polymers that spontaneously degrade and disappear under environmental conditions when their effectiveness has ended and can be re-applied after a suitable lifespan have been proposed.

For this research, sodium sulfate was selected and used as the crystallizing salt. The reason for this choice is that sodium sulfate is one of the most damaging salts in architectural heritage $[22,24,25]$ and the most used in laboratory studies on salt weathering [5].

The first part of the study was devoted to the selection of the best polymer candidates to develop this innovative stone conservation treatment. Then, the research was structured in two parts:

a. screening tests, aimed at evaluating specific features of the polymers and their compliance with the requirements stated above. Aqueous solutions of different polymers were prepared and tested to assess:

- the influence of the polymer on the crystallization temperature of sodium sulfate in solution, where supersaturation was achieved by cooling;

- the adsorption capability, surface morphology, resistance to water flow and influence on the crystallization of sodium sulfate of the polymers, when applied to different substrates.

The substrates selected were calcite and silica, as they are the main constituents of lithotypes widely used in historical architecture (e.g., limestone, sandstone). Calcite can undergo dissolution, which may initiate from defects in the polymer coating, causing the subsequent detachment and loss of the coating from the pore walls. This would destroy the effect of the polymer, so a pre-treatment of calcite with a solution of diammonium hydrogen phosphate (DAP), which inhibits dissolution [26, 27], was tested. This treatment was proposed for the conservation of carbonate stones [28-31] and it is based on the in-situ formation of hydroxyapatite (HAP) and other calcium phosphates $(\mathrm{CaP})$ on the carbonate substrate [32]. Besides providing a consolidating effect, the calcium phosphates formed in the stone have been shown to protect calcite from dissolution in both neutral and slightly acidic water [32], thus they are expected to play a positive role here. Moreover, the $\mathrm{CaP}$ phases formed over calcite are expected to act as anchoring substrates for the polymers. 
b. macroscale evaluation, aimed at investigating the effect of the polymers on stone. Some polymers selected in the screening tests were applied to limestone samples, with and without a pre-treatment with DAP solution. The stone samples were subjected to salt crystallization tests to investigate the effectiveness of the treatments.

\section{Polymers selected}

In compliance to the requirements highlighted in Sect. 2, we selected the following polymers (whose structures are reported in Figure S1-2, Supplementary material):

- poly(acrylic acid), in the form of sodium salt (Fluka, $M \mathrm{w}=2100$ ), labelled as "PAA";

- alginic acid, in the form of sodium salt (from brown algae, low density, low viscosity, Sigma Aldrich), labelled as "ALA";

- tannic acid (Sigma Aldrich), labelled as "TA";

- chitosan (from shrimp shells, low viscosity, Sigma Aldrich), labelled as "CHIT".

PAA is an anionic polyelectrolyte characterized by a main chain with negatively charged carboxylic groups (at neutral and alkaline $\mathrm{pH}$ ). It is water soluble, non-toxic and used as a scale inhibitor for calcium carbonate, calcium phosphate and calcium sulfate in alkaline environments. In fact, PAA is known to have a strong affinity with calcium carbonate owing to the presence of the carboxyl groups [21]. When used at high molecular weight for stone treatment, PAA exhibited a dramatic osmotic swelling leading to damage similar to that from salt crystallization [22], but at low molecular weight it gave good results in a series of Indiana limestone samples [21], hence it was considered promising for further testing.

ALA sodium salt is a linear copolymer of polyuronic acid composed of mannuronic and glucuronic acid residues characterized by a hydrophilic and colloidal behavior. The exact composition of this anionic polyelectrolyte depends on the source of the polysaccharide. Due to its biocompatibility, biodegradability and non-toxicity, it is employed in biomedical applications that benefit from the reactivity of its carboxylate side groups and its spontaneous gelation capacity when exposed to calcium ions (forming the so-called "egg box" structure) and to other divalent cations [33, 34].

TA is a natural polyphenol, which is a gallic ester of D-glucose in which gallic acid dimers totally esterified the hydroxyl groups of the carbohydrate. Its main applications are as antioxidant, hemostatic and antibacterial agent [35]. Tannic acid was selected for its interaction with gypsum [21], $\mathrm{SO}_{4}{ }^{2-}$ ions [36] and aragonite [37] due to the large numbers of carboxylic functional groups and to its ability to form a large amount of H-bonds.

CHIT is a biocompatible and antibacterial cationic polyelectrolyte, partially deacetylated form of chitin, a substance naturally found in the shells of crustaceans (e.g., shrimps) and exoskeletons of insects [38]. If combined with calcium carbonate, as in the shells of crustaceans and molluscs, chitin produces a much stronger composite, which shows better characteristics in terms of hardness and stiffness than pure chitin, and also higher toughness and ductility than pure calcium carbonate. Chitosan is a linear copolymer consisting of glycosidic linked D-glucosamine and N-acetyl-Dglucosamine units. When the ratio between D-glucosamine and $\mathrm{N}$-acetyl-D-glucosamine units (degree of deacetylation) [39] is close to 0.5, chitosan is soluble in aqueous acidic media. Chitosan is able to form oriented substrates for calcium carbonate growth [40] and moreover amine groups may act as a suitable anchoring site for silicate stone [21, 41].

\section{Materials and methods}

\subsection{Screening tests}

\subsubsection{Effect of the polymers on the crystallization of sodium sulfate in solution}

To evaluate the influence of the polymer and of its concentration on the crystallization of sodium sulfate, aqueous solutions of the salt alone and of the salt plus polymer (dosed in different concentrations) were prepared:

- 1 molal solution of anhydrous sodium sulfate $\left(\mathrm{Na}_{2} \mathrm{SO}_{4}\right.$, Panreac, reagent grade) ("SALTsolution"); 
- $0.1,1$ and 2 wt\% poly (acrylic acid) in SALTsolution ("SALT-PAA-0.1", "SALT-PAA-1" and "SALT-PAA-2", respectively);

- 0.1 and $0.5 \mathrm{wt} \%$ alginic acid in SALT-solution ("SALT-ALA-0.1" and "SALT-ALA-0.5", respectively). Lower concentrations with respect to the previous solutions were chosen, due to the lower solubility of this polymer;

- $0.1 \mathrm{wt} \%$ tannic acid in SALT-solution ("SALTTA-0.1"). Higher concentrations were discarded, as the polymer precipitated at $\mathrm{pH}$ close to neutrality;

- $0.1 \mathrm{wt} \%$ chitosan in acidified water $(10 \mathrm{mM}$ solution of glacial acetic acid), to which sodium sulfate was directly added ("SALT-CHIT-0.1"). This procedure was chosen because chitosan, differently from the other polymers, did not dissolve in the sodium sulfate solution.

Sodium sulfate precipitation was induced by cooling the saline solutions, owing to the strong dependence of sodium sulfate solubility on temperature. The aim was to investigate whether polymers display an interaction with the salt, thereby having a promoting or inhibiting effect on the nucleation of sodium sulfate. Hence, the solutions were cooled from $20{ }^{\circ} \mathrm{C}$ down to $2{ }^{\circ} \mathrm{C}$ at a constant rate $\left(\sim 0.5{ }^{\circ} \mathrm{C} / \mathrm{min}\right)$, in a reactor equipped with probes for the measurement of temperature, conductivity and $\mathrm{pH}$ of the solution (Metrohm, Gallen, Switzerland). The precipitation of the salt is easily detectable from a drop of conductivity and a sudden increase of the temperature, the phenomenon being exothermic, so the crystallization temperature was determined $\left(T_{\text {cryst }}\right)$. The $\mathrm{pH}$ probe was connected to an automatic titration system (Titrando 905, Metrohm, Gallen, Switzerland), keeping the $\mathrm{pH}$ of the solution in the range of $6-7$ by addition of a $\mathrm{NaOH}$ solution. The purpose was to investigate the crystallization temperature in $\mathrm{pH}$ conditions similar to reference saline solution and supposedly found in conservation, where acidic conditions must be avoided.

Seven replicate solutions were analysed for the reference SALT solution and three for all the other solutions, while just one replicate per run was used to identify the salt phase precipitated by X-ray diffraction (XRD) analysis (X'Pert PRO diffractometer, PANalytical, $\mathrm{Cu} \mathrm{K} \alpha$-radiation, current $=40 \mathrm{~mA}$, tension $=45 \mathrm{kV}$ ) performed immediately after the precipitation of the salt.

\subsubsection{Adsorption capacity of the polymers on different substrates (powders)}

The polymers were applied to different minerals to evaluate their adsorption capacity. As the layer of adsorbed polymer is expected to be thin and hence possibly difficult to quantify, the polymers were applied to powdered minerals, to exploit their large specific surface area to more easily quantify the amount of polymer.

The following powders were used as substrates for the polymer application:

- silica glass powder, obtained by manual grinding of microscope slides in a mortar ("glass");

- calcite powder (Panreac, reagent grade) ("calcite");

- calcite powder (same as above) treated with a solution of DAP ("calcite-DAP").

On the basis of previous studies [32], a DAP solution composed of $0.1 \mathrm{M} \mathrm{DAP}+1 \mathrm{mM} \mathrm{CaCl}_{2}+10 \mathrm{vol} \%$ ethanol in deionised water was used for the treatment. This low concentration of DAP associated with the presence of $\mathrm{Ca}^{2+}$ ions and ethanol is expected to contribute to the densification of the coating: indeed, this same formulation produced a basically complete coverage of a marble surface with a dense layer of octacalcium phosphate (OCP), and no traces of residual chloride after the treatment [32]. Calcite powder was left in the DAP solution for $24 \mathrm{~h}$ in a closed container, under constant magnetic stirring (powder:solution weight ratio equal to 1:50). Then, the powder was washed in deionized water, filtered and allowed to dry at room $T$.

The particle size and surface area of the powders used in the tests was determined by laser diffraction, LD (Malvern Mastersizer 2000 and Hydro 2000 MU unit as wet dispersing unit; preliminary dispersion of the powder in deionised water with few drops of surfactant Igepal ${ }^{\circledR}$ CA-630 by Sigma-Aldrich for $30 \mathrm{~s}$ with ultrasounds) and by nitrogen absorption at $77 \mathrm{~K}$ (BET method) (MicrometricTriStar).

The nature of the phases formed on calcite powder treated with the DAP solution was evaluated. This identification was very challenging, due to the small thickness of the newly formed layer (expectedly, some microns [32]) and hence the low amount of the phases investigated compared to calcite; moreover, some 
calcium phosphate phases exhibit very similar structures, which makes their identification difficult and requires a multi-analytical approach [42]. The methods used to identify the phases formed and their ability to prevent calcite dissolution are described in the Supplementary material (S2).

The application of the polymers to the powders was carried out in two steps:

- polymers were dissolved in ultrapure deionized water (MilliQ), except for chitosan, which was dissolved in $10 \mathrm{mM}$ glacial acetic acid aqueous solution. Acidic solutions were adjusted to $\mathrm{pH}$ 6-7 by adding a $\mathrm{NaOH}$ solution;

- $1 \mathrm{~g}$ of powder was added to $100 \mathrm{~mL}$ of polymer solution and kept under constant stirring for $1 \mathrm{~h}$.

The concentrations of the polymers were low in order to deposit thin polymer coatings on the powders surface, in view of the application to stone. In fact, the polymers are intended to form a thin layer on the stone pore walls to avoid pore blocking and drastic changes of stone microstructure. The following polymer concentrations were used:

- 0.2 and $0.5 \mathrm{wt} \%$ for PAA;

- $0.2 \mathrm{wt} \%$ for ALA;

- $0.01 \mathrm{wt} \%$ for TA, after a series of preliminary tests which indicated that higher concentrations produce a strong color alteration of the powder, unacceptable in the conservation field;

- $0.05 \mathrm{wt} \%$ for CHIT, bringing the solution to a $\mathrm{pH}$ equal to 7 by addition of $\mathrm{NaOH}$. Higher concentrations were discarded, as they led to the precipitation of chitosan at $\mathrm{pH}>7$.

From each dispersion of powder in the polymeric solutions:

- $50 \mathrm{~mL}$ were filtered under vacuum and dried at room temperature to obtain the dry powder to analyze. The treated powders were labelled according to the following scheme: substratepolymer-polymer wt\% concentration (e.g., GLASS-ALA-0.2);

- $15 \mathrm{~mL}$ were placed in a reactor and subjected to ultrapure water flow $(1 \mathrm{~mL} / \mathrm{min})$ under constant magnetic stirring for 10, 30 and $60 \mathrm{~min}$. Afterwards, the dispersions were filtered by gravity $(0.22 \mu \mathrm{m}$ filter $)$ and the solids were dried at room
$T$ prior to further analysis. The aim was to evaluate whether the adsorbed polymer layer remains on the surface or is completely solubilized. In the latter case, the treatment should obviously be considered useless. This aspect is very important to evaluate, as the polymers used are water soluble, but it is expected that upon adsorption their concentration in solution is strongly reduced. The treated powders subjected to the water flow were labelled according to the following scheme: substratepolymer-polymer wt $\%$ concentration-duration of water flow in minutes (e.g., GLASS-ALA-0.2t60).

The presence of the adsorbed polymer on the surface of the treated powders was investigated by attenuated total reflectance-Fourier transform infrared spectroscopy (ATR-FTIR; Jasco Model 6200, with MIRacle TM diamond crystal). Thermo-gravimetric analysis, TGA (Mettler-Toledo TGA/DSC1, analysis in air, heating rate $20^{\circ} \mathrm{C} / \mathrm{min}$ ), was also performed on the powders to quantify the amount of polymer adsorbed. Polymer powder (from the same batches used to prepare the solutions for the treatments) and the untreated powders were analyzed as well, for comparison's sake. After subjecting the treated powders to the water flow for different times, the same analyses were carried out on the powders, to evaluate the possible removal of the polymer by water washout.

\subsubsection{Morphology of the polymer coatings on carbonate substrates}

The ability of the polymers to form a continuous coating over the investigated minerals is very important, as it influences its ability to suppress the disjoining pressure between salt crystals and pore wall. Thus, the degree of coverage of the substrates by the polymeric coatings was investigated by applying the polymers over flat surfaces of the minerals and performing an analysis by atomic force microscopy (AFM). At this stage of research, the test was focused on the carbonate substrates, in view of the tests on limestone, so samples of calcite and calcite treated with the DAP solution were used. Thus, the following substrates were used: 
- calcite fragments obtained by cutting an Iceland spar crystal along the cleavage plane $\{10 \overline{1} 4\}$, having size of about $4 \times 4 \mathrm{~mm}^{2}$;

- the same calcite fragments, treated with the DAP solution.

The polymeric solutions used in the tests were those described in Sect. 4.1.2.

The fragments of each substrate were immersed for $1 \mathrm{~h}$ in a volume of polymer solution, (according to the proportion sample weight $(\mathrm{mg})$ :polymer solution volume (mL) equal to $10: 1)$. Then, the fragment was extracted with tweezers, rinsed by three quick immersions in deionised water, and placed for $1 \mathrm{~min}$ on a filter paper (treated face up) to remove the solution.

To evaluate the possible impact of the rinsing procedure on the coating, an additional sample (calcite-PAA-0.2) was not rinsed and was tested as it was. The same sample was then put into pure water for 1 min and analysed again.

Atomic force microscopy analysis (AFM) was carried out in a microscope NX20 by Park Systems working in tapping mode on areas of $20 \mu \mathrm{m} \times 20 \mu \mathrm{m}$, complemented by zooming of smaller areas. Both phase and topography images were obtained per each scan. For image processing and calculations, the software XEI, Park Systems, was used.

\subsubsection{Influence of the polymer coatings on the crystallization of sodium sulfate}

Thick coatings of the different polymers were deposited on a flat surface to investigate some properties of the polymers alone (independently from the substrate). The polymeric solutions described in Sect. 4.1.2 were used. Big drops $(50 \mu \mathrm{L})$ of each polymeric solution were deposited on glass slides and completely dried in sheltered conditions (in a container with a cover), without rinsing. These samples are labelled with the name of the polymer alone: PAA, ALA, TA and CHIT. The static contact angles of a drop of ultrapure water and a drop of sodium sulfate saturated solution over the coatings were measured, using the sessile drop method, by means of an OCA system (Dataphysic Contact angle system, software SCA20, Filderstadt, Germany). A drop volume equal to $4 \mu \mathrm{L}$ was used for both liquids. Each contact angle value was calculated as the average of 6 measurements carried out in different locations, $10 \mathrm{~s}$ after the drop deposition.

Similarly, the entire surface of the circular glass slide (3.2 cm diameter) was covered by a large amount of each polymeric solution ( $1 \mathrm{~mL})$ allowing it to dry completely in covered conditions, with no rinse. A drop of saturated sodium sulfate solution was released onto the dried coating, and its evaporation was followed by analyzing the morphology, spreading and nature of the solid phases progressively forming. The nature of the phases was monitored by in-situ XRD (explored area $2 \theta=5-50^{\circ}, \sim 6$ min per scan), measuring temperature and relative humidity inside the chamber at the beginning and end of each crystallization test by a portable thermo-hygrometer. The morphology and spreading of the salt crystals formed during the evaporation of the saturated saline solution was observed in situ using a polarized light optical microscope, OM (Leitz, Laborlux 12 Pol), on two replicate samples. The temperature and the relative humidity near the sample were measured during each test by a portable thermo-hygrometer.

Subsequently, thin polymer coatings were applied over the three selected substrates (glass, calcite and calcite-DAP) to investigate the joint behavior of the substrate and the coating. The polymeric solutions described in Sect. 4.1.2 were applied onto:

- the same glass slide described above;

- $4 \times 4 \mathrm{~mm}^{2}$ calcite fragments (the same described in Par. 4.1.3);

- $4 \times 4 \mathrm{~mm}^{2}$ calcite fragments treated by DAP (the same described in Par. 4.1.3).

At the end of the polymeric solution application, the samples were rinsed to remove any polymer excess, put for $1 \mathrm{~min}$ on a filter paper (treated face up) to remove the solution and finally allowed to dry at room temperature in covered conditions. After that, a drop of supersaturated sodium sulfate solution was released onto the treated and untreated slides and fragments, and the morphology of the salt crystals formed during the evaporation of the supersaturated saline solution was observed by OM, as described above. 


\subsection{Tests on stone samples}

\subsubsection{Materials and treatments}

The stone selected for salt crystallization tests was Globigerina Limestone, freshly quarried from the Qrendi area, Malta (Franka type, supplied by Xelini Skip Hire and High-up Service). This organogenic limestone is mainly composed of calcite, with traces of quartz and other impurities [28]. Cubes (side $5 \mathrm{~cm}$ ) and prisms $\left(3 \times 3 \times 25 \mathrm{~cm}^{3}\right)$ were cut, washed with deionized water and dried at $40{ }^{\circ} \mathrm{C}$ for 5 days. Half of the samples were subjected to the same DAP treatment described above, by partial immersion in the DAP solution for $24 \mathrm{~h}$, followed by drying at room conditions.

Stone samples with and without DAP treatment were treated with the polymeric solutions described above. For PAA, a concentration $0.5 \mathrm{wt} \%$ was selected, to improve the coverage of the coating with respect to that found for $0.2 \mathrm{wt} \%$ in AFM analysis (see Sect. 5.1.3). For ALA a concentration $0.2 \mathrm{wt} \%$ was selected, as the polymer exhibited some difficulty in dissolving in the concentration $0.5 \mathrm{wt} \%$. TA and CHIT were used in a very low concentration ( $0.01 \mathrm{wt} \%$ for TA and $0.05 \mathrm{wt} \%$ for CHIT), in the first case to avoid the color change noticed in calcite and in the second case due to the low solubility of the polymer. In the case of PAA $0.5 \mathrm{wt} \%$, the $\mathrm{pH}$ of the solution was 8.5 , while the $\mathrm{pH}$ of the other solutions was adjusted by addition of $\mathrm{NaOH}$ to 7.1, 6.5 and 6.6 for ALA $0.2 \mathrm{wt} \%$, TA $0.01 \mathrm{wt} \%$ and CHIT $0.05 \mathrm{wt} \%$, respectively. The treatment was applied by the same procedure used for the DAP solution (viz., by partial immersion for $24 \mathrm{~h}$, and drying for 1 week at laboratory conditions). Untreated samples of Globigerina limestone are labelled "GL-UT", while samples treated with the DAP solution are labelled "GLDAP"; for samples treated with polymers "GL" or "GL-DAP" is followed by "-polymer".

Anhydrous sodium sulfate was dissolved in ultrapure water, to prepare a saturated solution to be used in the tests.

\subsubsection{Methods}

The stone used in these tests was characterized by XRD, gas volumetric determination of $\mathrm{CaCO}_{3}$ amount by $\mathrm{HCl}$ attack (Dietrich-Frühling method), and mercury intrusion porosimetry (MIP) on two replicate samples (Fisons Macropore Unit 120 and Porosimeter 2000 Carlo Erba).

During the application of the polymer treatments, the following parameters were measured: mass of the samples before the treatment $\left(m_{0}\right)$, after the waterbased treatment application, so in wet condition $\left(m_{1}\right)$ and after the final drying $\left(m_{2}\right)$; ultrasonic pulse velocity, UPV (Controls Cernusco, $55 \mathrm{kHz}$ ), across the samples before and after the treatment. These parameters indicate the vol\% of solution absorbed (through the difference $m_{1}-m_{0}$ and the solution and stone densities), the mass change due to the adsorbed polymer $\left(\Delta m=m_{2}-m_{0}\right)$, the dynamic elastic modulus $\left(E_{\mathrm{d}}=\rho \cdot \mathrm{UPV}^{2}\right.$, where $\rho$ is the bulk density of stone).

The first crystallization test was carried out on the cubic samples (three replicates for each condition), by subjecting them to sodium sulfate crystallization cycles. Each cycle ( $24 \mathrm{~h})$ is composed of $4 \mathrm{~h}$ immersion in saturated sodium sulfate solution (14 wt\%), $8 \mathrm{~h}$ at $T=20^{\circ} \mathrm{C}$ and $\mathrm{RH}=85 \%$ (in ventilated climatic chamber), $10 \mathrm{~h}$ at $T=20{ }^{\circ} \mathrm{C}$ and $\mathrm{RH}=30 \%$ with convection (in a ventilated climatic chamber) and $2 \mathrm{~h}$ at room temperature.

During the immersion phase, the three replicate samples were kept in a container with $1 \mathrm{~L}$ of saline solution, whose level was kept constant by adding deionized water during the entire test. Then, the three samples were put into a single vessel and moved to the climatic chamber. Afterwards, the samples were gently brushed to remove stone debris and efflorescence, which were collected in the vessel and put in the corresponding container with the saline solution used for the soaking phase. In this way, the amount of salt during the test was kept constant. At the end of the first cycle, when no stone detachment was present yet, the efflorescence formed over the samples surface was gently brushed, collected and weighed $\left(w_{\text {dry }}\right)$; the amount of efflorescence per unit area of the samples was then calculated $(E / A)$. Sixteen cycles were carried out, weighing the samples after each cycle. At the end of the test, the samples were oven dried for 1 week at $40{ }^{\circ} \mathrm{C}$ and the final mass of the samples with respect to the initial one $\left(\Delta w_{\text {dry,final }}\right)$ was determined.

Differently from the standard procedure in EN 12370 [43], this procedure does not involve any oven drying in the crystallization cycles, which often leads to fast and unrealistic damage patterns, such as 
damage in the bulk of the specimens [5]. Nevertheless, the test is very severe, as it promotes the crystallization of sodium sulfate in the hydrated form (mirabilite, but possibly also sodium sulfate heptahydrate), causing damage mechanisms similar to those affecting real stone elements. Moreover, a saturated sodium sulfate solution was used, instead of the $10 \mathrm{wt} \%$ solution adopted in the EN 12370 test. This is expected to increase the amount of damage at each cycle.

The second crystallization test was based on the continuous capillary absorption of a sodium sulfate solution by the sample, with concomitant evaporation ("wick effect") [44], reproducing the typical supply of salt during rising damp. The test consists in partially immersing a vertical prismatic sample $\left(3 \times 3 \times 25 \mathrm{~cm}^{3}\right)$ in $200 \mathrm{~mL}$ of saturated sodium sulfate solution (Figure S1-3, Supplementary material). The solution is prevented from evaporating by a layer of paraffin. One sample for each condition was tested.

During the test, temperature was in the range $23-25{ }^{\circ} \mathrm{C}$ and $\mathrm{RH}$ was in the range $36-52 \%$, due to daily thermal excursion. The position of the samples was rotated on a daily basis, to average the possibly different evaporation rates in different locations of the laboratory. All the experimental setup was weighed every day to measure the loss by evaporation. The test ended when no more saline solution was available in the container (starting from day 13). Then, the samples were brushed to remove debris and efflorescence, oven dried at $40{ }^{\circ} \mathrm{C}$ for 1 week and brushed again. The stone debris were collected and their mass was measured $\left(m_{\text {lost }}\right)$ after removing the salts. Salts and stone debris were immersed in $1 \mathrm{~L}$ of deionized water to dissolve the salt and separated by filtration and drying.

\section{Results and discussion}

\subsection{Screening tests}

\subsubsection{Effect of the polymers on the crystallization of sodium sulfate in solution}

In agreement with the phase diagram of sodium sulfate, XRD analysis of the precipitated sodium sulfate confirmed that both in the absence and presence of the polymers, sodium sulfate precipitated in the form of mirabilite.
Values of $T_{\text {cryst }}$ of the solutions with the salt alone and with the salt and polymer are reported in Table 1, for the different concentrations selected. The degree of supersaturation $(\sigma)$ and its variation $(\Delta \sigma \%)$ with respect to the supersaturation of the reference saline solution calculated for the different solutions on the basis of the phase diagram are reported in the table as well. Supersaturation degrees were obtained considering the concentration of saturation of mirabilite in correspondence of the mean crystallization temperature obtained for each salt-polymer system analysed.

In the solution with salt alone (SALT-solution) sulfate crystallization occurred at $13.1^{\circ} \mathrm{C}$, but a significant standard deviation was found $\left(1.3^{\circ}\right)$. PAA seems to give a slight promoting effect on salt nucleation $\left(T_{\text {cryst }}\right.$ between 13.2 and $14.4{ }^{\circ} \mathrm{C}$ for the different concentrations), although an increase of about $+1{ }^{\circ} \mathrm{C}$ is comparable to the standard deviation found for the SALTsolution. The most significant effect was obtained for the intermediate concentration of $1 \mathrm{wt} \%$, thus a direct correlation of the effect with the polymer concentration was not found. In the SALT-ALA solutions a systematic decrease of $T_{\text {cryst }}$ was found, which suggests that ALA has some inhibiting effect on salt nucleation (see also supersaturation values in Table 1). The SALT-TA-0.1 solution did not exhibit any alteration of the crystallization temperature compared to SALT-solution. In the case of CHIT-SALT-0.1, part of the polymer precipitated in the solution strongly increasing its viscosity, but no salt precipitation occurred during cooling, hence the polymer may have a strong inhibiting effect on salt nucleation.

Inhibition of crystallization relies on a mechanism related to the presence of polymer chains adsorbed at the crystal growth sites. Crystal nuclei are probably enwrapped by the polymer chains, avoiding their growth. This mechanism has not been totally clarified yet [45]. Chitosan is a cationic polyelectrolyte, so it can be expected to selectively interact with the $\mathrm{SO}_{4}=$ ions, unlike the other polymers, which are anionic polyelectrolytes that interact with the $\mathrm{Na}^{+}$ ions. The binding of the $\mathrm{SO}_{4}=$ groups might possibly prevent the precipitation of salt crystals due to a steric hindrance effect, obviously more relevant for sulfate ions with respect to the smaller $\mathrm{Na}^{+}$ions. The inhibiting effect of chitosan in solution may be ascribed to the fact that its polyelectrolytic nature renders available a high number of positively charged sites that sequester sulfate ions, thus obstructing salt 
Table 1 Crystallization temperature $\left(T_{\text {cryst }}\right), \mathrm{pH}$ at salt precipitation and calculated supersaturation values $(\sigma)$ and its variation $(\Delta \sigma \%)$ with respect to the supersaturation of the reference saline solution of the different solutions

\begin{tabular}{|c|c|c|c|c|c|}
\hline Solution & Polymer concentration ( $w \%$ ) & $T_{\text {cryst }}\left({ }^{\circ} \mathrm{C}\right)$ & $\mathrm{pH}$ at salt precipitation & $\sigma$ & $\Delta \sigma(\%)$ \\
\hline \multirow[t]{2}{*}{ SALT-solution } & No polymer & $13.1 \pm 1.3$ & $6-6.1$ & 1.23 & - \\
\hline & 0.1 & $13.2 \pm 1.3$ & 6.6 & 1.22 & -1 \\
\hline \multirow[t]{2}{*}{ SALT-PAA- } & 1 & $14.4 \pm 1.1$ & $6.6-6.7$ & 1.12 & -9 \\
\hline & 2 & $14.0 \pm 0.9$ & $6.6-6.7$ & 1.16 & -6 \\
\hline \multirow[t]{2}{*}{ SALT-ALA- } & 0.1 & $11.7 \pm 1.7$ & $6.4-6.6$ & 1.37 & +11 \\
\hline & 0.5 & $7.6 \pm 4.5$ & $6.5-7.3$ & 1.92 & +56 \\
\hline SALT-TA- & 0.1 & $13.2 \pm 0.7$ & $6.6-6.7$ & 1.22 & -1 \\
\hline SALT-CHIT- & 0.1 & No precipitation & $6.5-7.2$ & $>2.78$ & $>126$ \\
\hline
\end{tabular}

For SALT-CHIT no salt precipitation took place during the time span of the experiment (36 min)

crystallization, which is confirmed by the fact that no crystallization occurred in the test. However, studies conducted on phosphonate [16] revealed that a polymer that inhibits salt crystallization while in solution may promote salt crystallization when it is adsorbed on a surface, owing to polymer chain orientation. All in all, these results show that the selected additives have a direct interaction with salt nuclei/crystals due to the presence of different functional groups in their polymer chains. It is thus expected that those that more strongly interact with pre-nucleation species (i.e., nucleation inhibition) would also display a more pronounced effect on their interaction with the salts once they are adsorbed on a substrate (i.e., crystallization promotion) [16].

\subsubsection{Adsorption capacity of the polymers on different substrates (powders)}

The particle size distribution of the powders is reported in Table 2. Glass powder, being obtained by manual grinding, is the most heterogeneous powder (i.e., having the broadest range of particle sizes).
Calcite powder exhibits a much smaller mean particle size than glass. Calcite-DAP powder exhibits a slightly larger mean particle size than calcite $(31 \mu \mathrm{m}$ instead of $18 \mu \mathrm{m})$. However, the specific surface area (SSA) of calcite-DAP powder found by BET analysis is two and three orders of magnitude larger than calcite and glass, respectively.

The nature of the phases formed after the treatment of calcite powder with the DAP solution is discussed in the Supplementary material S2. It was possible to identify the presence of hydroxyapatite (HAP) and octacalcium phosphate (OCP). As both these phases exhibit lower dissolution rate and lower solubility than calcite [32] and they limit calcite dissolution (Supplementary material S2), the treatment was considered successful. The roughness of the highly porous and nanostructured $\mathrm{CaP}$ layer formed over calcite particles (Fig. 1) explains the high specific surface area of the calcite-DAP powder found by BET [26].

ATR-FTIR analysis was used to assess the presence of polymers over the surface of the three kinds of powders. Notwithstanding the relatively high surface area of some of the powders, the amount of the

Table 2 Results of DLS and BET analyses on powders

\begin{tabular}{|c|c|c|c|c|c|}
\hline \multirow[t]{2}{*}{ Powder } & \multicolumn{4}{|l|}{ DLS analysis } & \multirow{2}{*}{$\begin{array}{l}\text { BET analysis } \\
\text { SSA }\left(\mathrm{m}^{2} / \mathrm{g}\right)\end{array}$} \\
\hline & Particle range $(\mu \mathrm{m})$ & $\mathrm{dV}(10)(\mu \mathrm{m})$ & $\mathrm{dV}(50)(\mu \mathrm{m})$ & $\mathrm{dV}(90)(\mu \mathrm{m})$ & \\
\hline Glass & $1.3-563.7$ & 57.3 & 126.3 & 247.9 & $0.037 \pm 0.005$ \\
\hline Calcite & $4.0-282.5$ & 9.2 & 17.9 & 33.9 & $0.258 \pm 0.018$ \\
\hline Calcite-DAP & $8.0-100.2$ & 17.6 & 31.0 & 53.6 & $25.761 \pm 0.887$ \\
\hline
\end{tabular}

$\mathrm{dV}(n)$ indicates the particle diameter corresponding to $n \%$ of the cumulative volume. SSA is the specific surface area of the powder 


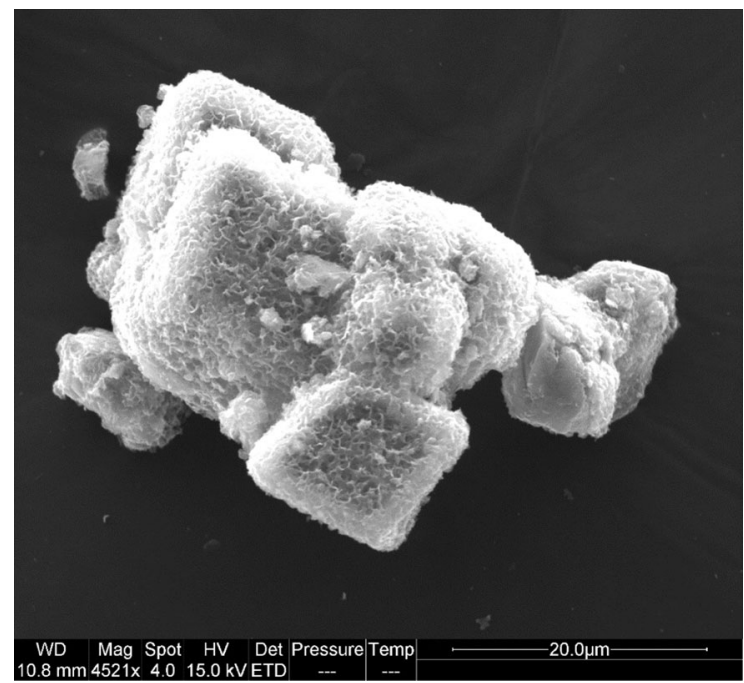

Fig. 1 SEM image of calcite particles with a rough $\mathrm{CaP}$ phases layer (see Supplementary material S2)

different polymers was close to the detectability limit for this technique. However, it was possible to detect some bands ascribable to their presence (such as $\mathrm{C}-\mathrm{H}$ stretch at $\approx 2900 \mathrm{~cm}^{-1}$ and bands related to the amine group in the case of CHIT, as $\mathrm{N}-\mathrm{H}$ bending at $\approx 1650 \mathrm{~cm}^{-1}$ and $\mathrm{N}-\mathrm{H}$ stretching at $\approx 3000-3500 \mathrm{~cm}^{-1}$ ), indicating that all the polymers were present in the powders even after the longest exposure to water flow (60 $\mathrm{min})$.

TGA was used to quantify the amount of adsorbed polymer, by comparing the weight losses of the polymers alone, untreated powders and powders with the polymers. In the calculation, we took into account the fact that PAA and ALA were analyzed as supplied (i.e., in the form of sodium salt), but they were applied to the inorganic powders in the form of aqueous solutions, hence only a fraction of the initial polymer mass is expected to be adsorbed on the powder; this was considered when comparing the weight loss of the polymers alone and that of the treated powders. The amount of each polymer in the powders before and after exposure to water flow, calculated on the basis of the TGA results, is reported in Fig. 2, while more details about the results of TGA are reported in the Supplementary material S3.

In the case of glass powder, an amount of chitosan equal to $5.5 \mathrm{wt} \%$ was present after the treatment, while the other polymers were present in an amount of about 1-2 wt $\%$. This higher amount of chitosan seems related to the well known film-forming capability of this polymer, which forms compact coatings [46] and exhibits the tendency to arrange itself in layers [47]. After only $10 \mathrm{~min}$ of exposure to the water flow, a significant amount of polymer was washed out, for all the polymers investigated, while for longer exposures no further washout seems to occur. This confirms that the excess polymer is solubilized, but a thin adsorbed layer remains on the glass. After $60 \mathrm{~min}$ exposure to water flow, the amount was basically the same for all the polymers and only slightly higher for CHIT. Based on these amounts and assuming a uniform distribution of the polymers on the surface of the powder, the thickness of the polymer layer can be roughly calculated, considering the densities of the polymers and silica glass and the specific surface area of the powder found by BET analysis (SSA $\approx 0.037 \mathrm{~m}^{2} / \mathrm{g}$ ). Although this estimation is quite simplified, it provides a rough estimate of the polymer thickness that is quite similar for ALA, TA and PAA (thickness $\approx 50$, 60 and $80 \mathrm{~nm}$, respectively), and almost 5-10 times larger $(\approx 500 \mathrm{~nm})$ for CHIT.

On calcite powder, TA, PAA and ALA produced a thinner layer $(\approx 25 \mathrm{~nm}$ for $\mathrm{TA}$ and $\mathrm{PAA}$ and $\approx 10 \mathrm{~nm}$ for ALA), while CHIT was adsorbed as a thicker layer $(\approx 840 \mathrm{~nm}$ ); however, no polymer was significantly affected by the water flow (in contrast to the case of the glass substrate), even for the longest exposure time. The slight increase of the amount of adsorbed chitosan for the longest washing time in Fig. 2a, b is just an indicator of the sensitivity of the TGA determination. The results in Fig. 2 indicate that the polymers exhibit different adsorption mechanisms and stability on the different substrates, possibly due to the structural/compositional features of each individual polymer and the different occurrence of physi- or chemi-sorption, or a combination of both. Moreover, it was recently demonstrated [47] that the properties of the chitosan adsorption layers formed on silica from aqueous solutions depend on several factors and primarily on the $\mathrm{pH}$ : while mild acidic conditions lead to rigid and thin monolayers, in neutral solutions layers become significantly thicker and are characterized by a highly hydrated state (up to $95 \%$ water). Therefore, minor $\mathrm{pH}$ variations during the test (e.g., a slight $\mathrm{pH}$ increase due to partial dissolution of calcite; see AFM results below), may have influenced the results. The adsorption mechanisms of the polymers control the thickness and coverage of the polymer 
Fig. 2 Amount of polymer (wt $\%$ ) deposited on the powders before the exposure to water flux (time 0) and retained after increasing times of exposure to water $(10,30$ and $60 \mathrm{~min})$ : a glass powder; $\mathbf{b}$ calcite powder; c calcite-DAP powder
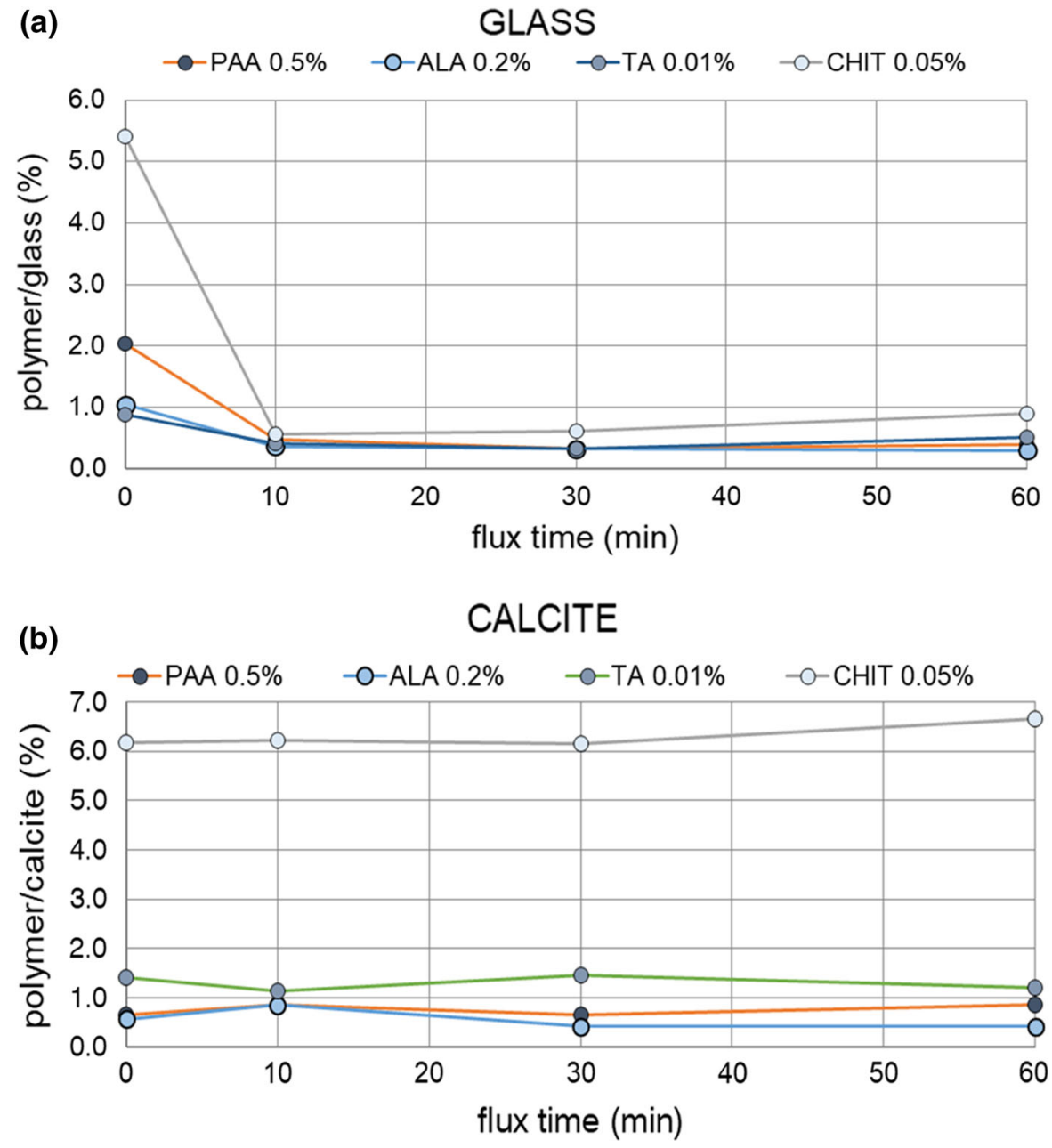

(c)

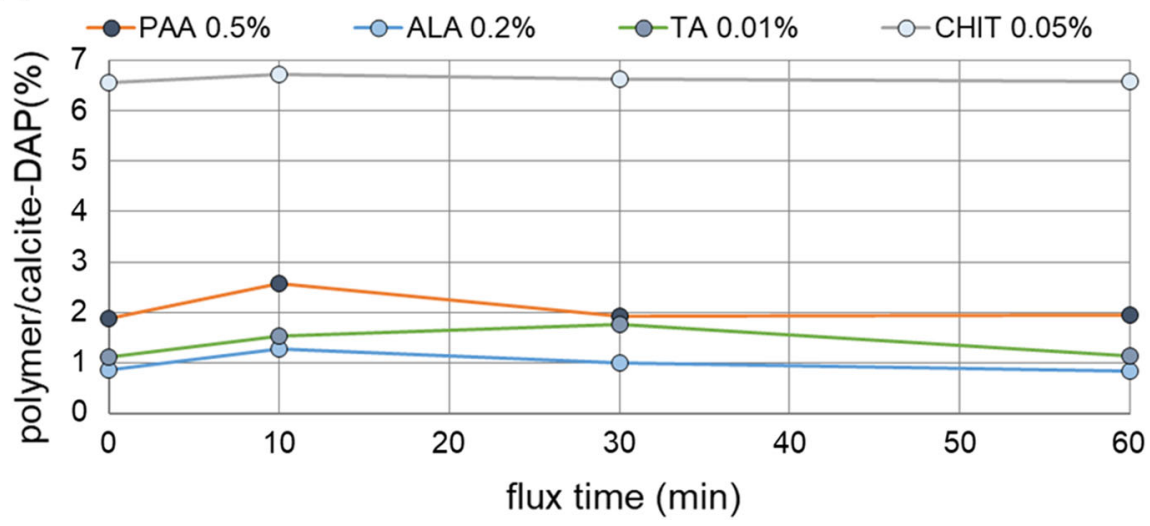

coatings, but such mechanisms were not specifically addressed in this study, so further investigations will be necessary to elucidate them.
In the case of calcite-DAP powder, the adsorption of the polymers seemed to be promoted as compared with bare calcite, probably due to the roughness of the 
$\mathrm{CaP}$ layer and the resulting higher SSA. As for calcite, polymer adsorption did not seem to be affected by the water flow. In this case, the estimation of the polymer thickness was not performed, as the specific surface area of calcite-DAP powder $\left(\mathrm{SSA} \approx 25.76 \mathrm{~m}^{2} / \mathrm{g}\right.$ ) is ascribed to the extreme roughness of the calcium phosphate phases formed, while the mean size of the particles changed to a minor extent. So, as the polymer most likely does not cover the entire calcium phosphate surface area, the calculation of the thickness was discarded as possibly misleading.

The adsorption test was aimed at evaluating whether the chemical nature of the mineral (silica, calcite or calcite-DAP) influences the polymers' adsorption and their possible washout, so it cannot be used to directly predict the thickness of the polymer

(a)

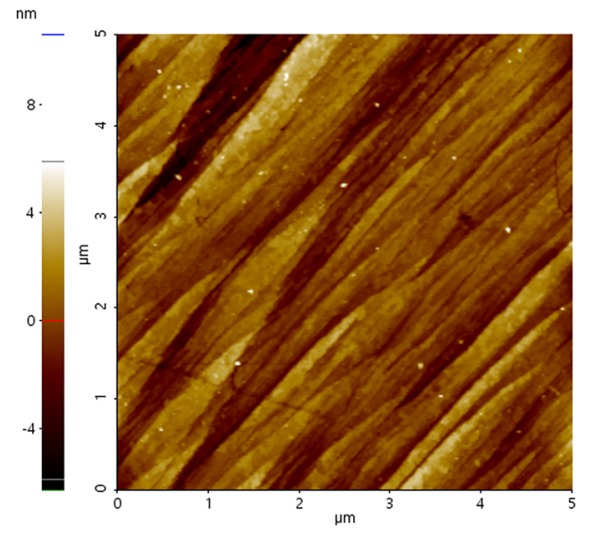

(c)

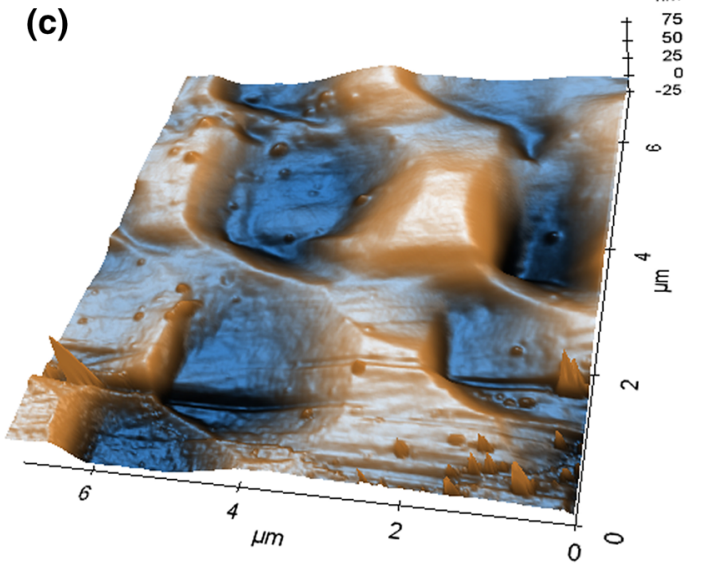

Fig. 3 AFM images of: a calcite surface, with no polymer treatment (topography image); b calcite-DAP surface, with no polymer treatment (phase images in enhanced colors overlapped to the $3 \mathrm{D}$ representation of topography); c calcite-PAA- 0.2 layer adsorbed in real stone, because this will be affected by several parameters depending on the nature of the stone, such as the pore size distribution, the interconnectivity and roughness of pores, the presence of secondary minerals, etc.

\subsubsection{Morphology of the polymer coatings on carbonate substrates}

Some representative AFM images of the calcite and calcite-DAP surfaces, both untreated and treated with the polymers, are shown in Figs. 3 and 4, while additional images are reported in the Supplementary material S4. Carbonate substrates were analysed in view of the tests on limestone, and no attempt to perform a detailed AFM study of the glass-polymers

(b)

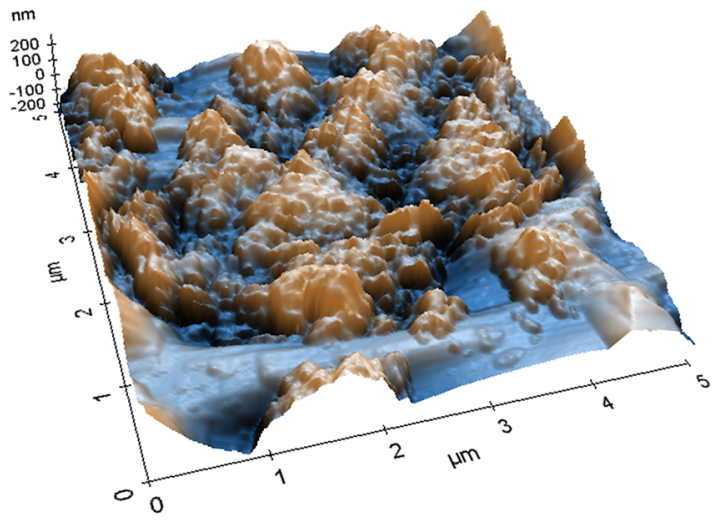

(d)

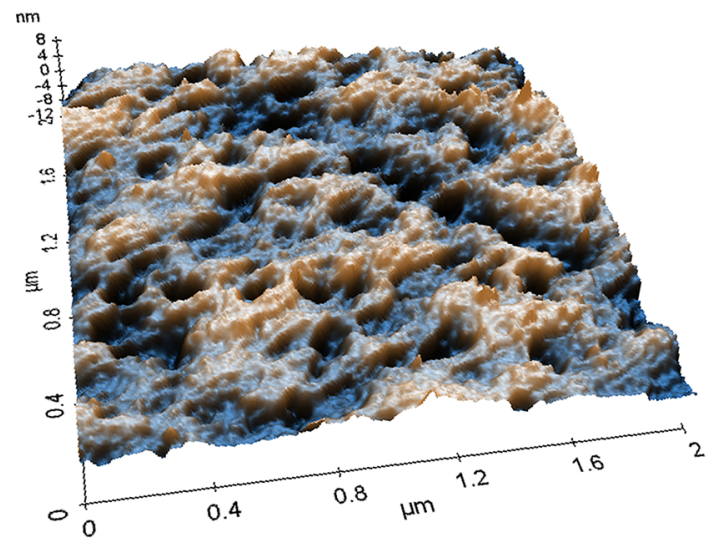

surface (phase images in enhanced colors); $\mathbf{d}$ calcite-ALA-0.2 surface (phase images in enhanced color). Note the higher roughness and etch pit density in $\mathbf{d}$ as compared with $\mathbf{c}$ 
systems was done due to the difficulty of obtaining nanometer-scale smooth ( $z$-axis) surfaces. Note that such nanometer-scale flat surfaces were readily obtained following cleavage of calcite crystals along the (10.4) planes.

The formation of new phosphate phases, spread across the calcite surface and characterized by high roughness, was observed in the calcite-DAP fragments (Fig. 3b, compared to Fig. 3a). For the surfaces treated with the polymers, the interpretation of the images was quite difficult, especially for the calcite-DAP substrate. In fact, for this substrate, there were challenges related to both the phase analysis, due to the presence of a three-phase system (calcite, calcium phosphate phases, polymer), and the morphology analysis, due to the highly texturized surface of the calcium phosphate phases (huge variations along z-coordinate). However, the main results of AFM observation and analysis can be summarized as follows:

- When applied over calcite, both PAA $0.2 \mathrm{wt} \%$ and ALA $0.2 \mathrm{wt} \%$ (Fig. 3c, d) accumulated preferentially along the two obtuse sides of the rhombohedral etch pits of calcite, consistent with what observed in a study on the effect of alginic acid on calcium carbonate dissolution [48]. Moreover, a higher number of etch pits was observed on the treated calcite surface as compared with the untreated one. The same study [48] suggested that alginic acid increases the dissolution rate of calcite in correspondence to the obtuse angles of the etch pits, hence PAA and ALA could have promoted calcite dissolution during the rinsing of the samples in water, although to a different extent (the etch pits observed on calcite-ALA- 0.2 were ten times smaller than those observed on calcite-PAA-0.2). To confirm this, an additional calcite fragment was treated with PAA $0.2 \mathrm{wt} \%$ and not rinsed in water: AFM analysis revealed that only a few etch pits were present over the surface (Figure S4-3, Supplementary material). The AFM observation was repeated after leaving the same fragment for $1 \mathrm{~min}$ in water, and new etch pits were found that were comparable to the ones initially observed in calcite-PAA-0.2 (rinsed); a strong reduction of the polymer coating was also observed (Figure S43, Supplementary material). The fact that the contact with water can dissolve both calcite and the accumulated polymer layer could result in an incomplete coating coverage, which is a possible drawback of these two treatments. This also confirms the necessity of introducing a coupling/ protecting layer, such as the one formed by DAP application. In fact, in calcite-DAP-PAA- 0.2 and calcite-DAP-ALA-0.2 fragments, etch pits were almost absent, confirming the positive action of $\mathrm{CaP}$ phases in reducing calcite dissolution. Moreover, in the same samples, the polymers preferentially accumulated around the agglomerates of phosphate phases having high elevation (Fig. 4a, b) and produced a smoother final surface as compared with calcite-DAP (Fig. 3b), also indicating a better coverage of the coatings.

- TA treatment in concentration $0.01 \mathrm{wt} \%$ produced a quite uniform distribution of the polymer over calcite, but also some zones of accumulation having a crust-like appearance (Figure S4-4, Supplementary material). When applied to calcite-DAP (Fig. 4c), TA formed a coating that made the surface smoother than untreated calcite-DAP, suggesting a better retention of the polymer over the rough $\mathrm{CaP}$ layer.

- A thick chitosan layer was observed both in calcite-CHIT-0.05 and calcite-DAP-CHIT-0.05 samples (Fig. 4d), exhibiting a basically complete coverage of the surface, consistently with the results found in Sect. 5.1.2. The coating exhibited a granular appearance (Figure S4-5, Supplementary material). Chitosan caused a strong levelling of the surface with respect to untreated calciteDAP, although the final surface was still highly rough and structured (Fig. 4d).

\subsubsection{Influence of the polymer coatings on the crystallization of sodium sulfate}

The contact angles between water and polymer and between sodium sulfate solution and polymer are reported in Table 3. Contact angle is an important parameter to assess whether the polymers could alter the water transport properties of stone. Contact angles remained basically the same passing from water to sodium sulfate solution for ALA and slightly increased for PAA, TA and CHIT $\left(+5^{\circ},+7^{\circ}\right.$ and $\left.+10^{\circ}\right)$, respectively. PAA and TA exhibited a highly hydrophilic behavior. ALA and CHIT exhibited higher contact angles than the other polymers, but still in the 
(a)

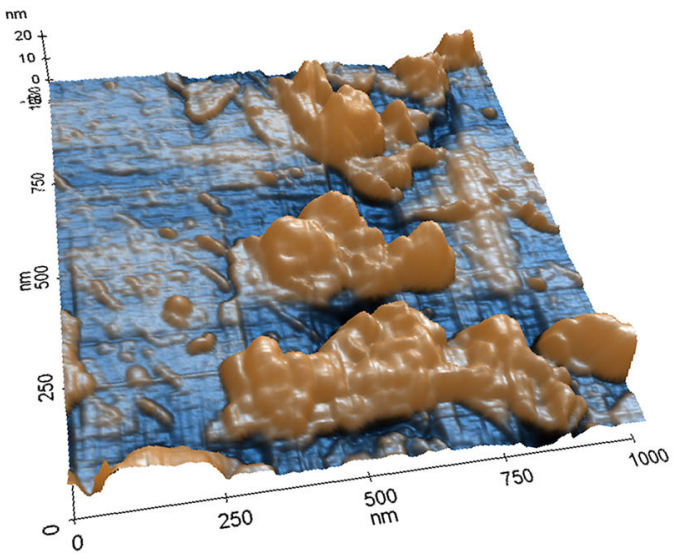

(c)

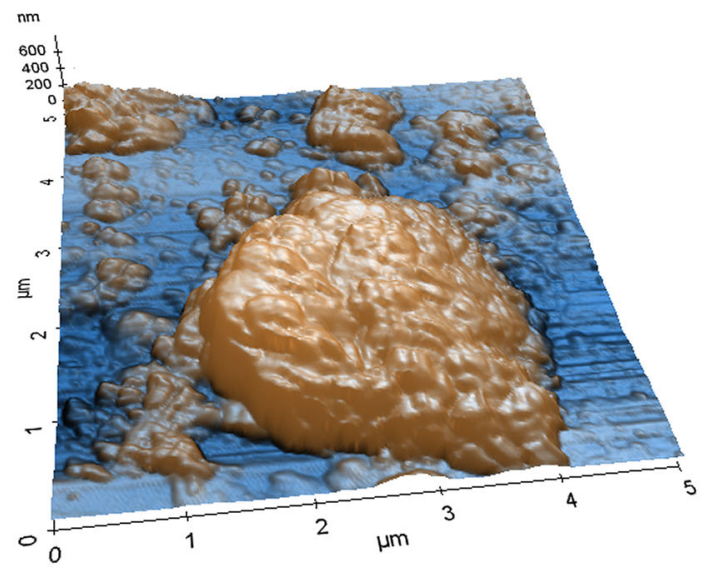

(b)

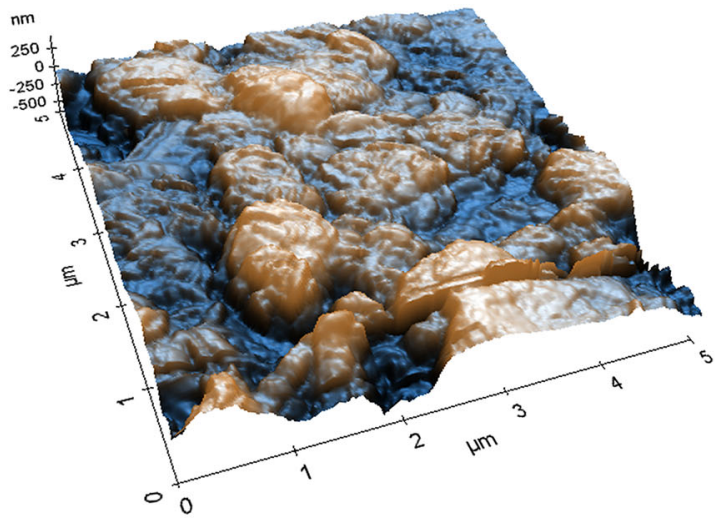

(d)

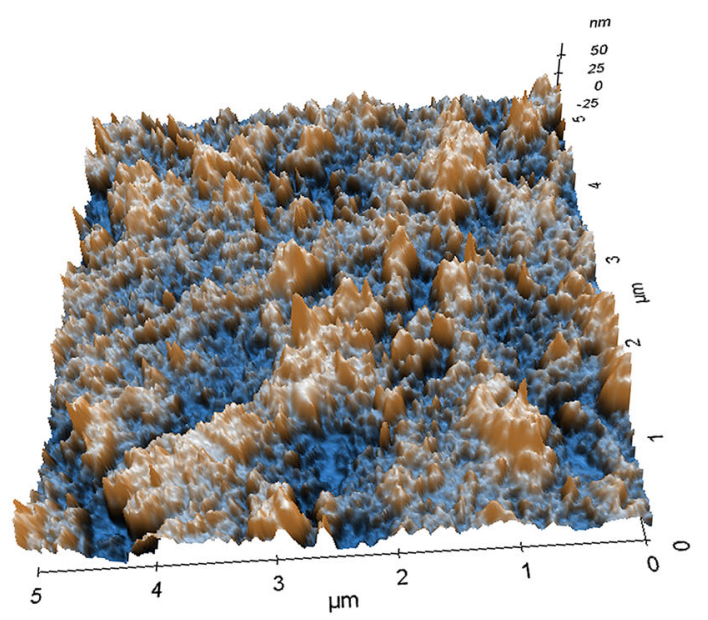

Fig. 4 3D AFM phase images (enhanced colors) of: a calcite-DAP-PAA-0.2; b calcite-DAP-ALA-0.2; $\mathbf{c}$ calcite-DAP-TA-0.01; d calcite-DAP-CHIT-0.05 . Note changes in vertical scale

Table 3 Contact angle between pure water and polymer coatings and between sodium sulfate solution and polymer coatings

\begin{tabular}{lll}
\hline Polymer & Contact angle, water $\left(^{\circ}\right)$ & Contact angle, sodium sulfate solution $\left(^{\circ}\right)$ \\
\hline PAA & $13 \pm 1$ & $18 \pm 1$ \\
ALA & $60 \pm 7$ & $60 \pm 8$ \\
TA & $13 \pm 3$ & $20 \pm 2$ \\
CHIT & $65 \pm 4$ & $75 \pm 4$ \\
\hline
\end{tabular}

hydrophilic range $\left(<90^{\circ}\right)$. The results confirm that the polymers give no hydrophobic behavior, so are not expected to dramatically alter the moisture transport properties of stone.

The in-situ XRD results and OM images obtained during the evaporation of a drop of sodium sulfate solution over the polymers (thick polymer coatings on glass slide) are reported in Fig. 5, respectively, while the phases found at each step, regardless of their amounts, are shown in Fig. 6. This crystallization test was repeated at the end of the tests, using new samples of (thin) polymer coatings over glass slides; results are 


\section{PAA}

(a)

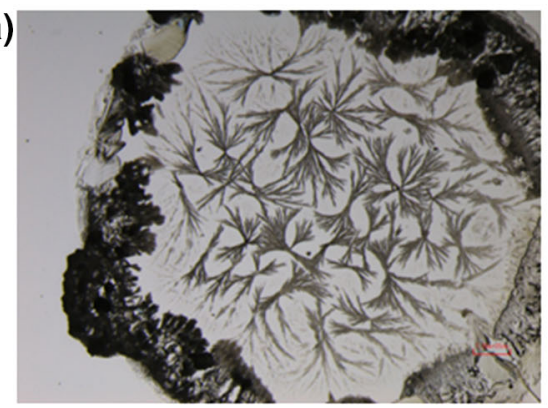

$\mathrm{CHIT}$

(c)

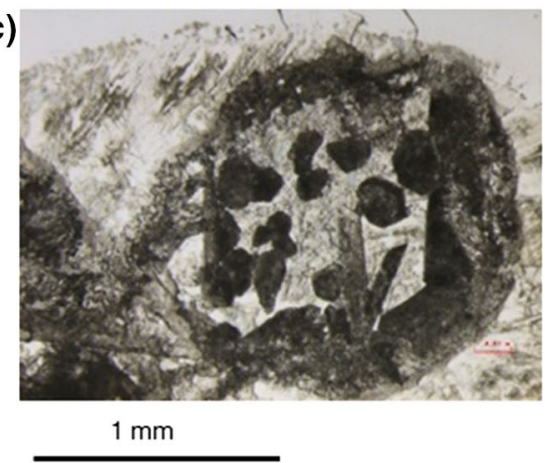

ALA

(b)

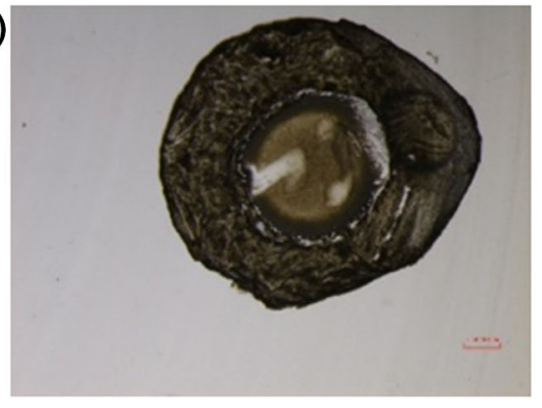

$\mathrm{CHIT}$

(d)

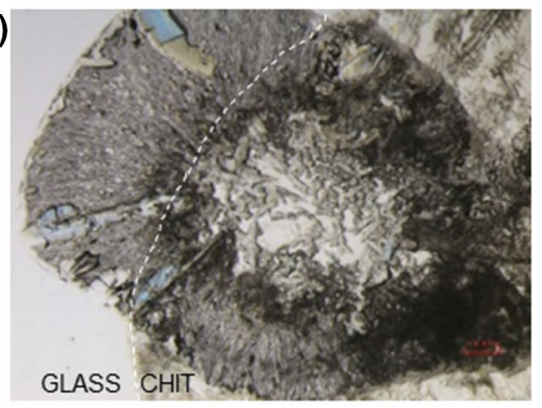

Fig. 5 Optical microscope images of the evaporation of a drop of sodium sulfate solution deposited over a thick layer of polymer $\left(T=27^{\circ} \mathrm{C}, \mathrm{RH}=32 \%\right): \mathbf{a}$ PAA; $\mathbf{b}$ ALA; $\mathbf{c}, \mathbf{d}$ CHIT (the dashed line indicates the border of the polymer coating)

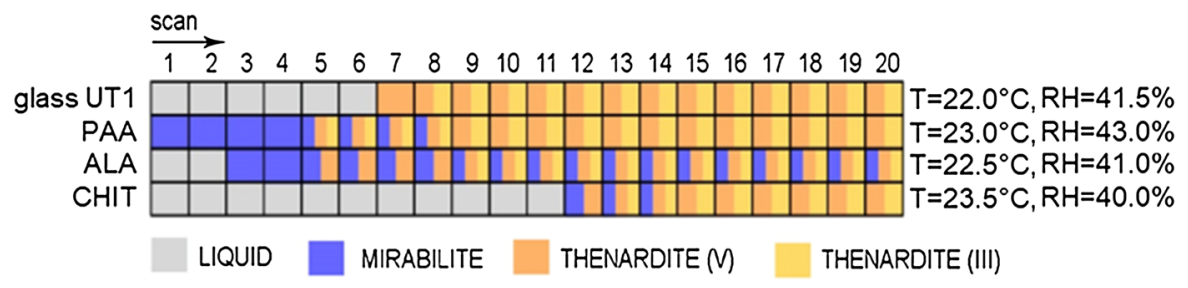

Fig. 6 Sodium sulfate phases detected at each XRD scan (scan duration 6 min) for untreated glass ("UT1") and for thick layers of polymer applied on flat glass substrates (PAA, ALA and CHIT). Environmental conditions during the test are also reported

reported in Figs. 5 and 6. At that time, TA had already been discarded due to the color change found in the selected stone (Sect. 5.2), hence the crystallization test was not carried out on TA and no results are available for TA in Figs. 5 and 6.

Some representative OM images collected during the observation of the evaporation of the salt solution deposited on the three substrates (glass slides, calcite and calcite-DAP fragments) are reported in Fig. 7. If the coating attracts the salt crystals, we expected that they would spread over the coating, whereas crystals were expected to grow at the air/solution boundary of the droplet for the untreated substrates, because at the edges of the droplet a maximum evaporation rate occurs leading to a high supersaturation which in turn fosters crystallization [21]. However, the morphology and spreading of sodium sulfate crystals formed during the evaporation of the solution was extremely difficult to interpret. Firstly, the environmental conditions ( $T$ and $\mathrm{RH}$ ) strongly influence the rapidity and the type of salt phase nucleating. Moreover, heterogeneities in the polymer coating, defects in the surface and surface roughness may also affect the location and the morphology of the precipitating salt, as 
schematically represented in Figure S1-4, Supplementary material. In fact, surface roughness plays a fundamental role regardless the chemistry of the surface. Moreover, the polymers involved are characterized by different contact angles with respect to the liquid phase, so the drop shape and the contact area were different among the samples during the test.
Nevertheless, some useful information was obtained also from the observed time evolution of crystallization, as salt precipitation was actually affected by the presence of the polymer, even if not uniformly distributed over the surface. Notably, the polymer coatings obtained by immersion treatment (or dip (a)

$$
\text { GLASS-UT }
$$

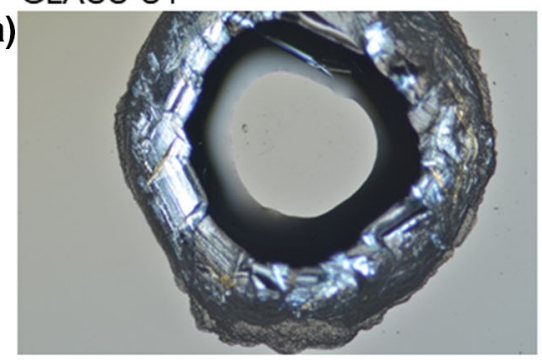

(c)
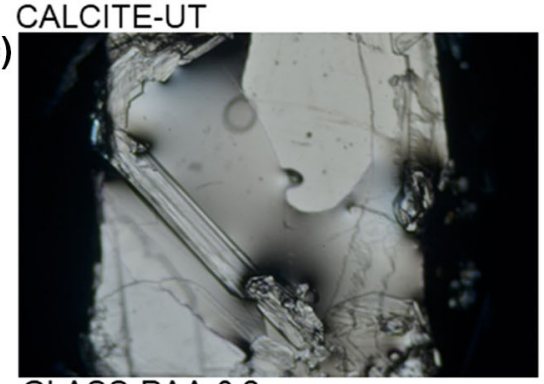

(e)
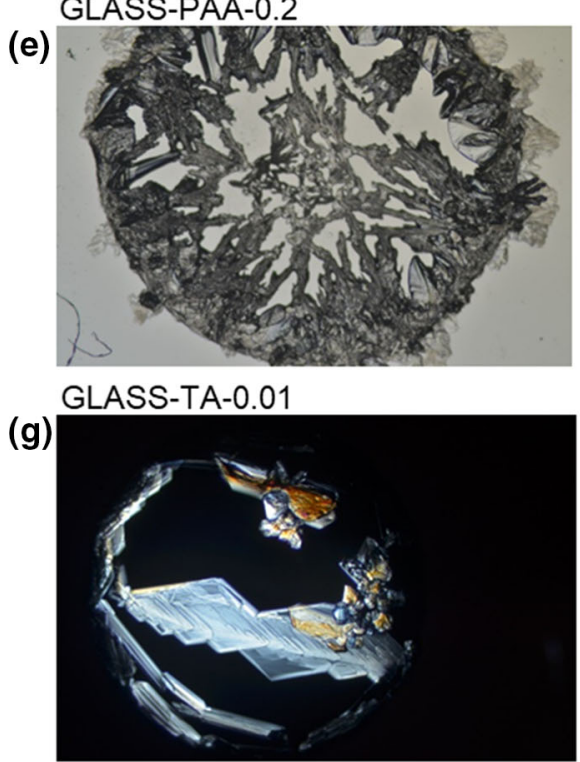

$1 \mathrm{~mm}$

Fig. 7 Optical microscope observations of the evaporation of a drop of sodium sulfate solution deposited over: $\mathbf{a}, \mathbf{b}$ untreated glass; c untreated calcite; d untreated calcite-DAP; e glassPAA-0.2; f glass-ALA-0.2; $\mathbf{g}$ glass-TA-0.01; h glass-CHIT- (b)

\section{GLASS-UT}

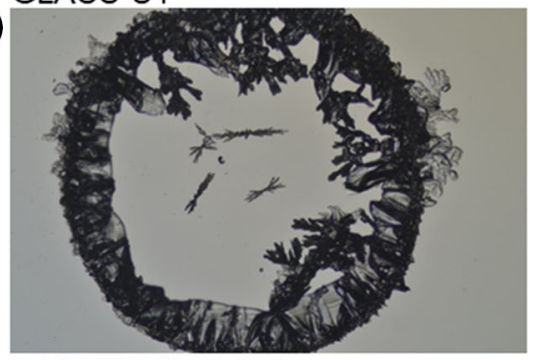

\section{CALCITE-DAP-UT}

(d)

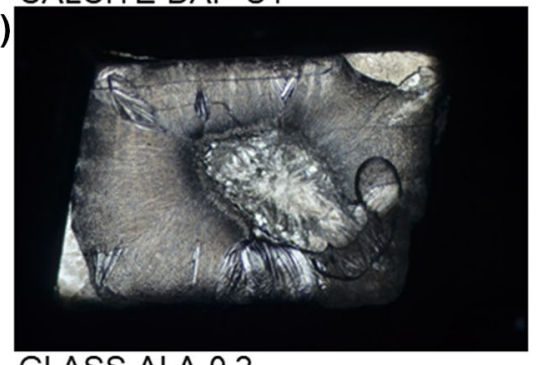

(f)

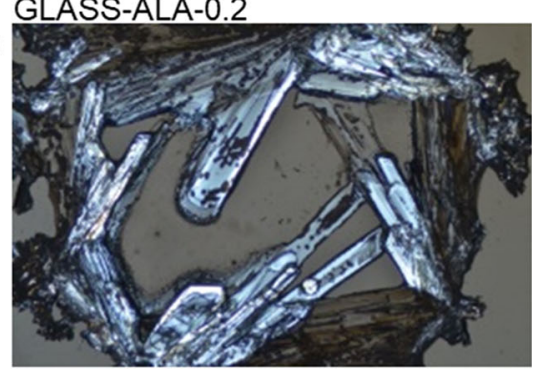

(h)

GLASS-CHIT-0.05

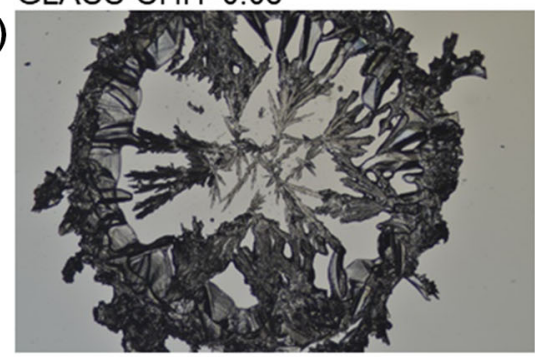

0.05. Analysis performed at: $T=23.5{ }^{\circ} \mathrm{C}, \mathrm{RH}=40 \%$ for $\mathbf{a}, \mathbf{c}-$ e and $\mathbf{h} ; T=28.5^{\circ} \mathrm{C}, \mathrm{RH}=29 \%$ for $\mathbf{b}, \mathbf{f}$ and $\mathbf{g}(\mathbf{a}, \mathbf{c}, \mathbf{d}, \mathbf{f}$ and $\mathbf{g}$ crossed polar images and $\mathbf{b}, \mathbf{e}$ and $\mathbf{h}$ are plain light images) 
coating) are expected to be much thinner than the thick polymer layers here obtained.

Based on the results, the following remarks can be made:

- In the untreated substrates (Fig. 7a-d), salt precipitation occurred mostly at the drop border, as expected. The presence of the rough $\mathrm{CaP}$ phases over the calcite surface (calcite-DAP sample) seems to promote the formation of needle-shaped crystals (Fig. 7d). In fact, sodium sulfate formed a ring of whiskers that grew from the drop border, first along the drop-air interface and then bowing towards the centre of the drop. In the centre of the drop some dendritic crystals finally formed owing to the high supersaturation values reached in the liquid film held within the surface roughness of $\mathrm{CaP}$.

- PAA and, to a minor extent, ALA promoted sodium sulfate nucleation with respect to the untreated substrates (glass in this case), as shown in Fig. 6. These two polymers promoted the nucleation of sodium sulfate also when applied over calcite and calcite-DAP substrates, as noticed during the OM observations. In the case of PAA, this result matches the behavior of the polymer in solution (Table 1), while the behavior observed for ALA in solution was the opposite (inhibiting rather than promoting salt nucleation). In the case of PAA and ALA, sodium sulfate crystals covered almost the entire drop contact area, spreading across the polymer coating, thus suggesting a good affinity between the salt crystals and the polymers (Fig. 5a, b). However, crystals also formed in the central area during the last stage of the drop evaporation, thus precipitation might have been influenced also by defects or roughness of the polymer coatings, as illustrated in Figure S1-4, Supplementary material. In the case of thin layers of PAA and ALA applied over different mineral substrates (Fig. 7e, f), the spreading of the salt crystals over the coatings was observed as well, although this effect was less defined than in the polymers alone (i.e., thick coatings) (Fig. 5a, b) and the crystals not only nucleated in contact with the coating, but also nucleated along the drop border and grew towards its centre, possibly also influenced by the presence of discontinuities in the polymer coating.
- CHIT clearly inhibited nucleation of sodium sulfate, as shown by in situ XRD results (Fig. 6). This was observed on every substrate and the salt crystals that can be observed over the polymer coating in Figs. 5c, d and $7 \mathrm{~h}$ did not nucleate and grow in contact with chitosan, although the 2D images may lead to misinterpretations. Actually, the crystals formed within the liquid, floated until the solution totally evaporated and finally were deposited on the surface. In the case shown in Fig. 5d, the sodium sulfate droplet partially fell outside the coated area (i.e., over the untreated glass) and the salt started to nucleate there, confirming the inhibitive action of chitosan towards salt nucleation.

- The OM observation of the TA coating applied over glass (Fig. 7g) suggested that some spreading of the salt crystal over the surface took place, but no conclusive indication about the promoting or inhibiting effect towards salt nucleation were found when this polymer was applied over calcite and calcite-DAP surfaces.

\subsubsection{Summary of the results of screening tests}

The results found in the screening tests allow us to make the following remarks:

- the pre-treatment with an aqueous DAP solution produced the formation of a layer of calcium phosphate phases over calcite. This layer, having the thickness of some microns, is formed mainly by OCP and HAP, both having lower solubility and dissolution rate as compared to calcite; consistently, the treatment reduced calcite powder dissolution in water. The DAP treatment induced significant superficial roughness, which seems also to affect the crystallization of sodium sulfate, although this aspect was not specifically addressed in this research. Further investigations will be carried out to isolate the effect of the surface roughness of the $\mathrm{CaP}$ phases from the surface chemistry induced by the DAP treatment on sodium sulfate crystallization, analysing the crystallization of sodium sulfate over smooth HAP crystals;

- the polymers are adsorbed in a higher thickness on glass than on calcite, which suggests that the absorption mechanisms of the polymers are 
different on different minerals, and possibly also that a single adsorption mechanism is influenced to a different extent by the characteristics of the substrates (e.g., roughness), although this aspect was not specifically investigated here. However, while in the case of glass, the excess polymer was easily washed out by water, in the case of calcite the thickness of the polymer layer was basically not affected by the exposure to water. Notably, in both the substrates, a thin and stable adsorbed polymer layer was present even after prolonged exposure to water flow. The thickness of the adsorbed chitosan layer was much higher than that of the other polymers (thickness about 10 times as much). This is likely due to its film-forming capability and tendency to adsorb on substrates as a multilayer coating due to its conformational / structural features and the establishment of H-bonds among the abundant functional groups. However, the mechanisms of chitosan adsorption from an aqueous solution was found to be quite complex, and strongly affected by the $\mathrm{pH}$ of the solution. In particular, at neutral $\mathrm{pH}$ the layer of chitosan adsorbed on a silica substrate was found to exhibit high thickness and a highly hydrated state [47], consistent with the results found here. The treatment with DAP increases the amount of all polymers adsorbed on calcite, probably due to the roughness of $\mathrm{CaP}$ phases, enhancing the adsorption;

- unexpectedly, AFM analysis showed that PAA (and to a minor extent ALA) treatment promotes the formation of etch pits on the calcite substrate, resulting in an incomplete coverage of the coating. This effect is not visible when the polymers are applied on calcite pre-treated with DAP, confirming the ability of the $\mathrm{CaP}$ layer in reducing calcite dissolution;

- the polymer coatings are all hydrophilic, so they are not expected to significant alter the water transport properties of stone, but PAA and ALA are highly hydrophilic (contact angle of $18-20^{\circ}$ ), while TA and CHIT exhibit higher contact angles $\left(60-75^{\circ}\right)$.

- during evaporation of a drop of sodium sulfate solution, PAA, ALA and, to a minor extent, TA coatings seem to promote the spreading of the salt crystals, suggesting that their affinity with salts may actually contribute to reducing the disjoining pressure between salt and pore wall (see the results of the stone salt crystallization tests, below). However, the effect of the polymers in terms of sodium sulfate crystal morphology was not clearly revealed, due to the strong influence of heterogeneities, surface roughness and environmental conditions on sodium sulfate crystallization in this kind of test. Distinguishing the role played by these factors from the polymer behavior is very challenging.

- While no clear influence of TA in promoting or inhibiting sodium sulfate crystallization was found, PAA and, to a minor extent, ALA promoted sodium sulfate nucleation when adsorbed over a mineral surface. Promotion of sodium sulfate nucleation leads to crystallization at lower supersaturation levels and further suggests a high physical-chemical affinity of these polymers with the salt. CHIT exhibits a strong inhibiting action towards sodium sulfate nucleation hence the salt crystallizes in the bulk solution or on substrate areas not covered by the polymer, rather than in contact with the polymer.

In light of the results of the screening tests, PAA, ALA and, possibly, TA are promising candidates to reduce the disjoining pressure between the growing salt and the pore wall, differently from CHIT. Nevertheless, the inhibiting action of CHIT towards sodium sulfate nucleation and its strong interaction with the mineral substrates are very interesting features. In particular, chitosan has never been tested as a protective treatment against salt weathering in stone and its inhibiting effect on sodium sulfate nucleation could be exploited to promote the formation of efflorescence rather than harmful subflorescence. For this reason, CHIT was also investigated in the following tests on stone samples.

\subsection{Tests on stone samples}

Based on XRD and determination of carbonate amount, Globigerina limestone is composed of $\mathrm{CaCO}_{3}$ (98\%), with traces of quartz. Based on MIP, the total open porosity of the stone is $31.47 \pm 1.06 \%$, the mean pore radius $3.3 \pm 0.13 \mu \mathrm{m}$ and the specific surface area $1.40 \pm 0.32 \mathrm{~m}^{2} / \mathrm{g}$. All of these values are consistent with what was reported for this type of stone $[28,29]$. 
The characteristics of the stone before and after the treatments are reported in Table 4. Variations of the sample mass were almost negligible for all the treatments, due to the low concentration of the solutions applied, producing thin coatings on the pore walls. However, slightly negative variations were found for GL-PAA (without DAP pre-treatment) and, mostly, for GL-TA (with and without DAP pretreatment), which might be due to some aggressive action of these solutions, confirmed also by the drop in $E_{\mathrm{d}}$. In fact, these treatments caused a strong color alteration of the samples and the polymeric solutions, as shown in Figure S1-5 of Supplementary material. A possible contribution of PAA to calcite dissolution of substrates and some reaction between TA and calcite (color change) were highlighted also in the screening tests. For this reason, TA was discarded in the following test. However, as the color alteration caused by PAA was totally inhibited by the DAP pretreatment, this polymer was investigated also in the subsequent tests. The treatment with DAP, ALA and CHIT caused a slight increase in $E_{\mathrm{d}}$, although comparable with the standard deviation for this parameter; only for CHIT applied post DAP this increase was more prominent.

The amount of solution absorbed after $24 \mathrm{~h}$ immersion ranged between 22.5 and 24 vol\% for all the treatments. Considering that the open porosity was $31.5 \%$, these values correspond to saturation degrees equal to $71 \%$ and $76 \%$, respectively, which means that the samples adsorbed the solutions to a great extent and basically all the pore volume of the samples was reached by the solutions, but the samples were not fully saturated, possibly because air bubbles were not completely removed and/or the finest pores were not completely filled in the $24 \mathrm{~h}$ soaking.

The amount of saline solution absorbed by the cubic samples after the first immersion in the saline solution was basically the same for all the treated samples and very similar to that of the untreated ones: $21 \pm 0.4$ vol\% for GL-UT; $20.8 \pm 0.1$ vol\% for GL-DAP; $20.4 \pm 0.1$ vol $\%$ for GL-PAA and $22 \pm 0.8$ vol $\%$ for GL-DAP-PAA; $20.6 \pm 0.0$ vol\% for GL-ALA and $20.9 \pm 0.2$ vol $\%$ for GL-DAP-ALA; $20.7 \pm 1.3$ vol $\%$ for GL-CHIT and $21.3 \pm 0.2 \mathrm{vol} \%$ for GL-DAPCHIT. This confirms that the polymer treatments do not significantly alter the absorption and transport properties of stone.

The weight change of the samples after each drying cycle (and brushing), $\Delta w_{\text {dry, } \mathrm{n}}$, is reported in Fig. 8, while the final dry weight (after oven drying, $\Delta w_{\text {dry,final }}$ ) with respect to the initial one is reported in Fig. 9a. The amount of efflorescence per unit area (E/A) formed at the end of the first cycle is reported in Fig. 9b. Measuring the amount of efflorescence is very important, as the place where salt accumulates (on the surface or just below it) strongly affects the damage in this kind of test. In fact, the damage observed in the wetting-drying cycles of the conventional sodium sulfate accelerated weathering test is considered to be caused mainly by the crystallization pressure exerted by mirabilite crystallizing at high supersaturation during the wetting phase of the cycle [2, 49]. However, the slight dry exfoliation observed in the climatic

Table 4 Characteristics of stone samples before and after the treatment: mass variation after the treatment, in dry condition $(\Delta m)$; amount of solution absorbed in the treatment; $E_{\mathrm{d}}$ (standard deviations in brackets)

\begin{tabular}{|c|c|c|c|c|c|c|}
\hline \multirow[t]{2}{*}{ Treatment } & \multirow[t]{2}{*}{ Substrate } & \multirow[t]{2}{*}{$\Delta m(\mathrm{~g})$} & \multirow[t]{2}{*}{ Absorbed solution (vol\%) } & \multicolumn{2}{|l|}{$E_{\mathrm{d}}(\mathrm{GPa})$} & \multirow[t]{2}{*}{$\Delta E_{\mathrm{d}}(\mathrm{GPa})$} \\
\hline & & & & Before & After & \\
\hline DAP & GL-UT & $0.17 \pm 0.23$ & $22.5 \pm 0.3$ & $12.3( \pm 0.6)$ & $12.4( \pm 0.5)$ & +0.1 \\
\hline \multirow[t]{2}{*}{ PAA } & GL-UT & $-0.11 \pm 0.03$ & $24.0 \pm 0.2$ & $12.7( \pm 0.4)$ & $12.4( \pm 0.4)$ & -0.3 \\
\hline & GL-DAP & $0.04 \pm 0.01$ & $23.5 \pm 0.5$ & $12.4( \pm 0.5)$ & $12.3( \pm 0.4)$ & -0.1 \\
\hline \multirow[t]{2}{*}{ ALA } & GL-UT & $-0.01 \pm 0.01$ & $23.9 \pm 0.2$ & $12.1( \pm 0.6)$ & $12.3( \pm 0.8)$ & +0.2 \\
\hline & GL-DAP & $0.00 \pm 0.00$ & $23.2 \pm 0.2$ & $12.7( \pm 0.5)$ & $12.8( \pm 0.6)$ & +0.1 \\
\hline \multirow[t]{2}{*}{ TA } & GL-UT & $-0.22 \pm 0.08$ & $23.4 \pm 0.2$ & $12.3( \pm 0.2)$ & $11.2( \pm 0.2)$ & -1.1 \\
\hline & GL-DAP & $-0.03 \pm 0.02$ & $23.5 \pm 0.2$ & $11.9( \pm 0.3)$ & $11.2( \pm 0.6)$ & -0.7 \\
\hline \multirow[t]{2}{*}{ CHIT } & GL-UT & $0.06 \pm 0.03$ & $24.0 \pm 0.3$ & $11.8( \pm 0.4)$ & $12.0( \pm 0.3)$ & +0.2 \\
\hline & GL-DAP & $0.01 \pm 0.02$ & $24.0 \pm 0.1$ & $11.8( \pm 0.2)$ & $12.5( \pm 0.6)$ & +0.7 \\
\hline
\end{tabular}


Fig. 8 Weight variation of the samples $\left(\Delta w_{\text {dry,n }}\right)$, with respect to initial dry value $\left(\Delta w_{\text {dry,n }}\right.$ was measured at each cycle, after residence in climatic chamber at low relative humidity): a samples treated with polymers alone; b samples treated with DAP and polymers, with respect to the untreated reference
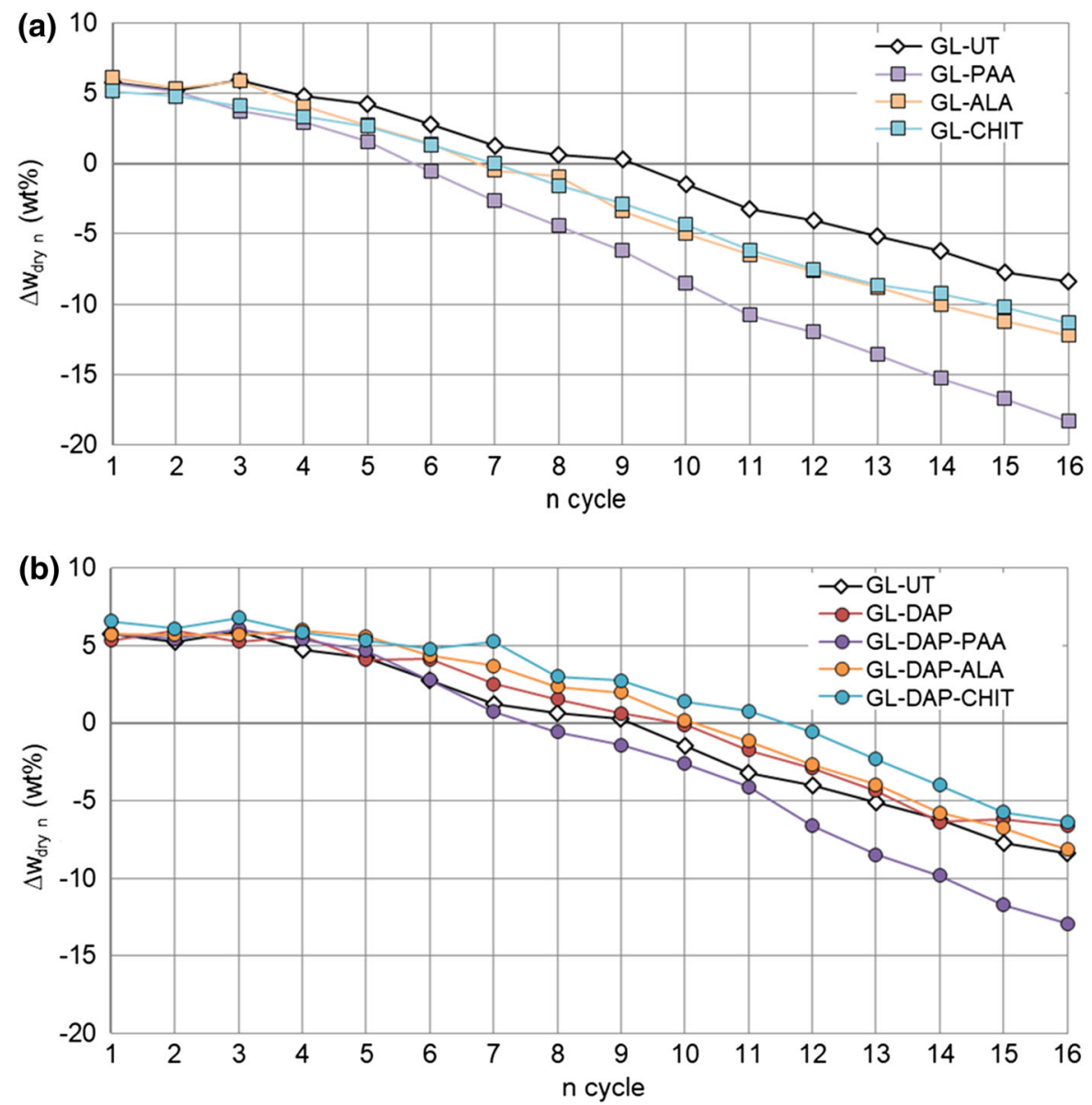

(a)

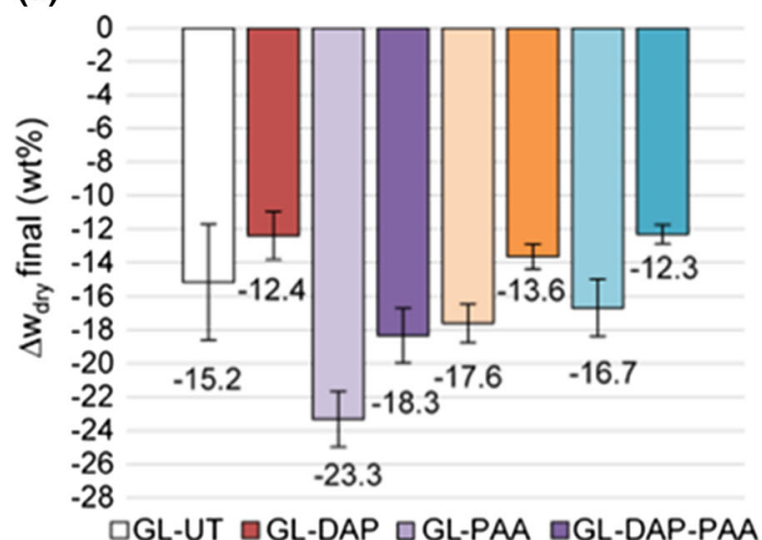

Fig. 9 a Final change in dry weight of the samples after oven drying at $40{ }^{\circ} \mathrm{C}$ for 1 week and brushing $\left(\Delta w_{\text {dry,final }}\right)$, with respect to initial one; $\mathbf{b}$ efflorescence per unit area formed on the (b)

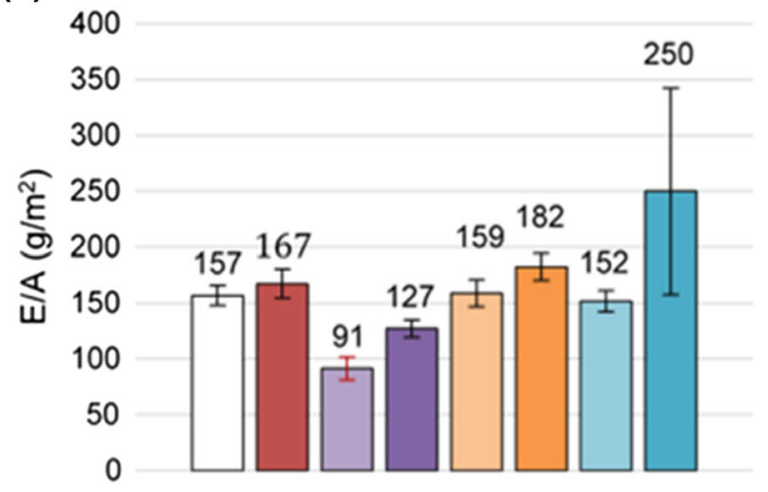

$\square G L-A L A \quad \square G L-D A P-A L A \quad \square G L-C H I T \quad \square G L-D A P-C H I T$

surface at the end of cycle $1(E / A)$. This latter value is slightly overestimated for samples GL-PAA, due to the presence of some stone debris 
chamber (dry cycle) is also related to the shrinking effect due to dehydration of mirabilite into thenardite, which results in a molar volume reduction of $-314 \%$ [29] and may produce some damage if it occurs near unconfined superficial layers of stone. Note however, that dehydration of mirabilite involves the formation of a highly porous thenardite pseudomorph and a small degree of bulk shrinkage [9, 50], which limits the above-mentioned dry exfoliation. The measurement of E/A was obviously possible only at the end of the first cycles, as after that stone debris detached from the samples.

The final weight loss of the samples, measured after oven drying and brushing ( $\Delta w_{\text {dry final }}$ in Fig. 9a), was systematically higher than the weight loss measured at the end of the 16th cycle ( $\Delta w_{\text {dry,n }}$ in Fig. 8 ), which means that the drying in the climatic chamber in each cycle did not completely remove the moisture from the samples. Thus, the weight variations reported in Fig. 8 also include the residual moisture present in the samples; when $\Delta w_{\mathrm{dry}, \mathrm{n}}$ starts to decrease, it means that the stone experiences a loss of material due to salt crystallization damage, this loss overcoming the salt (and moisture) accumulated during the impregnation phase.

The mean value of $\Delta w_{\text {dry,final }}$ (wt $\%$ ) was $-15.2 \pm 3.5 \%$ for the untreated samples (GL-UT), while the DAP treatment reduced this value to $-12.4 \pm 1.4 \%$ (GL-DAP samples), suggesting that the $\mathrm{CaP}$ phases alone increased the salt resistance of stone. The fact that DAP alone had a positive effect on the salt resistance of the stone (Figs. 8b and 9a) may be ascribed to several aspects, possibly acting together: an increase in the tensile strength of the stone [51], beneficial also for the resistance to salt [29]; the fact that a rough pore surface facilitates capillary flow toward the exterior surface [52], promoting the formation of efflorescence rather than harmful subflorescence, which is corroborated by the higher amount of efflorescence formed in DAP with respect to UT (and generally when DAP + polymers are used compared with the polymers only) (Fig. 9b); the preventive action towards calcite dissolution [32] which reduces the stone loss during the impregnation phase and the damaging side effects related to the joint action of chemical stone dissolution and salt weathering [9].

All the polymer treatments alone caused a worse performance when compared to the untreated samples.
In particular, the highest final weight loss was observed for GL-PAA $(-23.3 \pm 1.7 \%)$, followed by GL-ALA $\quad(-17.6 \pm 1.2 \%)$ and GL-CHIT $(-16.7 \pm 1.7 \%)$. Conversely, the presence of the pre-treatment with DAP improved the behavior of the polymer treatments. In the case of GL-DAP-PAA, the final dry weight loss was still slightly higher than for the untreated stone $(-18.3 \pm 2.6 \%)$, while the samples GL-DAP-ALA and especially GL-DAP-CHIT experienced lower weight losses compared with the untreated samples $(-13.6 \pm 0.7 \% \quad$ and $-12.3 \pm 0.6 \%$, respectively).

In terms of the cycle at which the damage starts, all the samples experienced some stone loss from the very first cycles: dry scaling was observed at cycle 1 for samples GL-PAA, at cycle 2 for samples GL-UT and GL-DAP, at cycle 3 for samples GL-DAP-PAA, GLALA and GL-CHIT, while at cycle 4 for samples GLDAP-ALA and GL-DAP-CHIT. It must be considered that this salt crystallization test is very aggressive, hence even a slight retarding effect may correspond to significant delay of the damage in the field. The harshness of the tests makes it difficult to assess whether the polymer treatments caused some significant delay in the damage onset; nevertheless, Fig. 8 clearly shows that $\Delta w_{\text {dry,n }}$ for samples GL-DAP-ALA and GL-DAP-CHIT was almost constant until the 6th and 8th crystallization cycle, respectively, while it started to decrease from the 4th cycle for GL-UT samples, suggesting that these two treatments noticeably delayed the onset of damage.

The worsening behavior observed for GL-PAA with respect to GL-UT (Figs. 8a, 9a) can be partially related to the promoting effect on calcite dissolution observed above and also to some reaction with the stone (revealed by the color change in Figure S1-5, Supplementary material). When applied after DAP, the behavior of GL-DAP-PAA improved and the weight loss was the same as for the untreated stone for the first seven cycles, but afterwards a worsening was still observed. Under the test conditions, the tendency observed for PAA to promote nucleation of sodium sulfate and to accumulate the salt under the surface, which is corroborated by the low amount of efflorescence observed, is counterproductive if the polymer coating is not continuous. In fact, while the promoting action of PAA towards sodium sulfate nucleation may reduce the supersaturation at which the salt crystallizes and its higher affinity may allow the salt to touch 
the pore walls covered by the polymer, it may be ineffective during impregnation, if the condition of high supersaturation for the hydrate phase is controlled by dissolution of thenardite. Indeed, if dissolution of thenardite accumulated in the previous cycle is fast [2], the crystallization of mirabilite will occur at a supersaturation related to thenardite saturation, which is inevitably high for the hydrated phase(s), due to the lower solubility of mirabilite and heptahydrate with respect to thenardite. In this case, if the polymer coating is not continuous, high pressure will be exerted between the hydrate salt and the uncovered area of the pore wall. Moreover, ALA alone, which seems to moderately enhance calcite dissolution, caused a worsening in terms of stone weight loss with respect to the untreated samples, but to a much lower extent than PAA, and in this case DAP-ALA samples behaved slightly better than UT (also causing a significant delay in the damage start). A possible explanation of the lower damage observed for GLALA compared with GL-PAA may be related to its less evident enhancement of sodium sulfate nucleation that slightly reduces the concentration of salt under the surface (producing a higher amount of efflorescence, Fig. 9b) and/or to a better coverage of the pore walls obtained with ALA and/or to a different accumulation of salt with respect to GL-PAA, owing to the lower contact angle of ALA compared with PAA. In fact, the different wettability of the polymers may influence the place where crystallization occurs during drying (i.e., just below or over the surface for low contact angle, and more in depth for contact angles approaching $90^{\circ}$ [21]). This is due to the fact that during evaporation large pores empty out, but in highly hydrophilic materials the solution is retained in small pores and a water film also wets the pore walls of larger ones. This provides a continuous network that allows the solution to flow towards the external surface (in the funicular stage of drying) [53]; this does not occur when the contact angle approaches $90^{\circ}$, causing an accumulation of salts in the interior of the sample.

In the case of CHIT, the effect of the polymer treatment alone is worse than the untreated stone (Fig. 9a), so the delaying action of chitosan on nucleation of sodium sulfate seems not sufficient to promote efflorescence. The delaying action of CHIT on sodium sulfate nucleation and its low affinity with the salt could even increase the damage if crystallization occurs inside the stone, as sodium sulfate will crystallize at higher supersaturation, thus exerting higher pressures on the pore wall [54]. However, the same CHIT treatment associated with DAP caused a clear improvement (Figs. 8b, 9a), probably because both CHIT and DAP promoted the formation of efflorescence instead of subflorescence, so in GLDAP-CHIT the two treatments successfully added their beneficial effects in a synergistic manner, thereby increasing the salt resistance of the treated stone.

The fact that the salt resistance is systematically improved when the polymers are applied after DAP (with respect to the polymers alone) seems also due to a more complete polymer coverage achieved in the presence of the CaP phases, as AFM analysis showed.

Concerning the salt crystallization test under continuous capillary absorption, the measurement of the water loss by evaporation (reported in Figure S1-6, Supplementary material) showed that no treatment altered significantly the rate of evaporation, as expected due to the absence of pore blocking effect and hydrophobicity. The relative humidity fluctuations during the test (in the range 36-52\%) make it difficult to say which solid phases formed, as mirabilite crystallizes between $40 \%$ and $50 \%$, while below $40 \%$ thenardite may directly precipitate from the solution [25]. The stone loss at the end of the test is reported in Fig. 10, while the aspect of the samples after the 13th day and after the final brushing is reported in Fig. 11, with some details in Fig. 12. Differently from the test involving crystallization cycles in cubes, the effect of the treatments in terms of stone deterioration is very clear. The untreated sample exhibited an evident mass loss and erosion due to salt damage in the upper part, where supersaturation conditions were reached inside the sample and salt precipitation occurred (Fig. 11a). The DAP treatment improved the resistance of the stone to salt damage (and fostered efflorescence formation), as suggested also by the previous test.

The treatment with PAA basically gave no beneficial effect, confirming what was found in the previous test, but its behavior improved significantly when combined with DAP, the mass loss being reduced by $-25 \%$ with respect to GL-DAP and, on the whole, $-78 \%$ compared with GL-UT (Fig. 10). For PAA alone, the salt exhibited a tendency to crystallize under the stone surface forming an interconnected layer of sodium sulfate crystals within the pore system (Figs. 11c, 12a); "globular" 
Fig. 10 Mass loss of the stone specimens (with reference to their initial dry mass) after the salt crystallization test under conditions of continuous capillary flow (13 days)

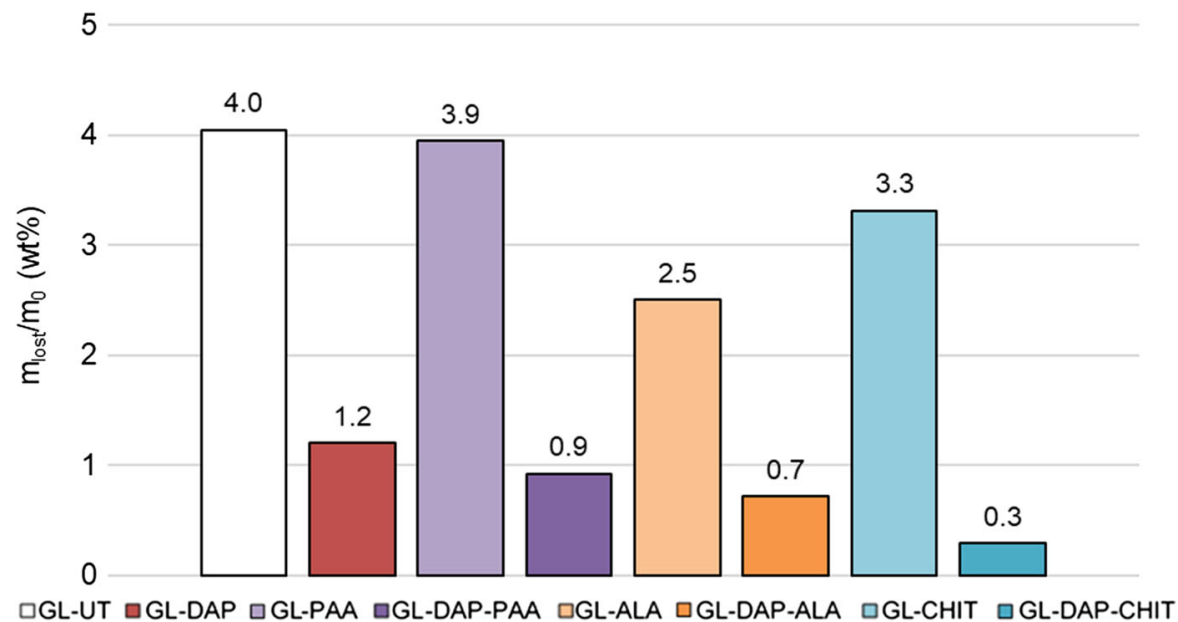

efflorescence formation was also observed. When PAA was associated with the DAP pre-treatment, the efflorescence formation was significantly enhanced; moreover, salt crystals in efflorescence displayed a needle-like shape (Figs. 11d, 12b).

The ALA treatment alone caused a significant decrease in the weight loss of stone $(-38 \%)$, although also in this case the formation of subflorescence was observed (Figs. 11e, 12c). This result suggests that the role of the polymer in minimizing the disjoining pressure with the salt is beneficial for the final damage in this kind of experimental set-up. The behavior was significantly better for GL-DAP-ALA (weight loss $-41 \%$ versus GL-DAP), and again a promoting effect towards efflorescence formation was evident (Figs. 11f, 12d).

Chitosan alone brought an improvement in terms of stone loss, which decreased by - 18\% compared with the untreated stone (Fig. 10), the inhibiting effect of CHIT being beneficial in this kind of test. The effect of the DAP-CHIT, where the two treatments added their promoting effect towards efflorescence formation, was outstanding, causing a mass loss reduction as compared to the untreated stone equal to $-93 \%$. The observation of the samples after brushing (Fig. 11h) confirmed the basic absence of damage.

The results of the macroscale tests are difficult to fully interpret at this stage of the research, as several factors seem to jointly play a role in the damage occurrence:

a. the positive effect of $\mathrm{CaP}$ phases in limiting salt damage, which may be ascribed to different mechanisms (as described above), among which the promotion of efflorescence is quite evident;

b. the ability of the polymers to form a continuous and defect-free coating over the pore surface;

c. the affinity of PAA and ALA with the salt crystal, expected to minimize the disjoining pressure;

d. the promoting action of PAA, and to a minor extent ALA, towards salt nucleation, which increases the amount of salt accumulating inside the sample: in the long run, this might cause some damage anyway (more quickly if the coating is not continuous);

e. the promoting action of PAA, and to a minor extent of ALA, towards calcite dissolution and some possible other reactions between stone and PAA (possibly owing to stone impurities which reacted with PAA producing the color change in Figure S1-5, Supplementary material);

f. the inhibiting action of CHIT towards salt nucleation, which may lead to the formation of efflorescence, but also the fact that this inhibiting effect may lead to very high supersaturation conditions inside the samples, which appears as a negative effect in harsh cyclic crystallization tests, such as the one performed on cubes in this research;

g. the synergy of CHIT and $\mathrm{CaP}$ phases to enhance efflorescence formations contributing to the success of the combined treatment;

h. the possibly different deposition of the polymer coatings in large and small pores. 


\section{(a)}

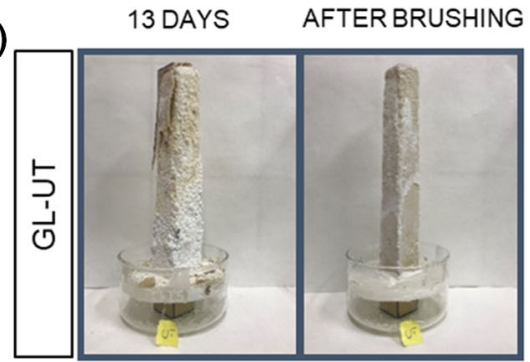

(c)

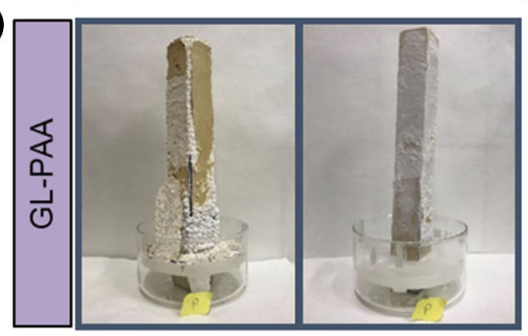

(e)

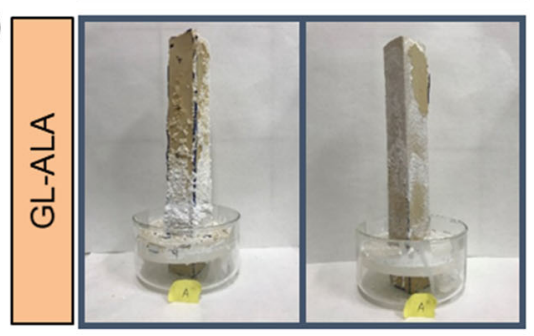

(g)

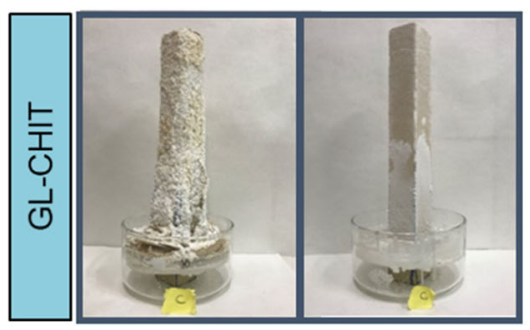

(b)

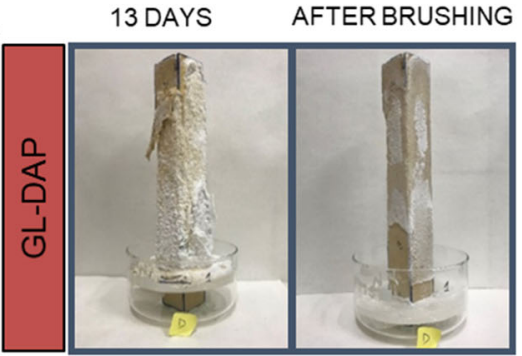

(d)

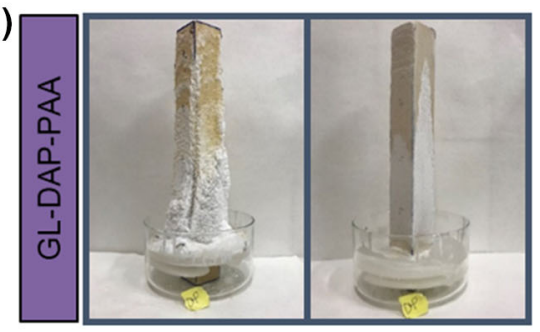

(f)

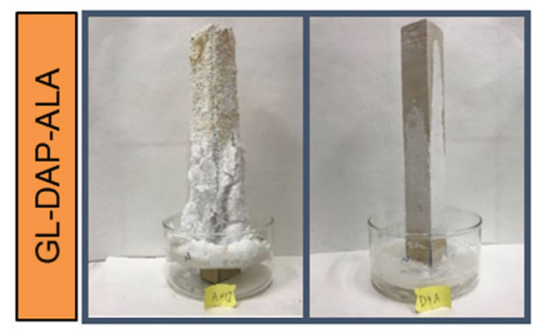

(h)

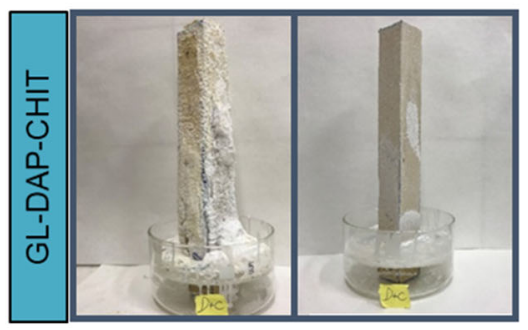

Fig. 11 Aspect of the stone specimens after 13 days of salt crystallization test under conditions of continuous capillary flow (left image) and after the final brushing (right image)

\section{Conclusions}

Based on the screening tests, which are summarized in Sect. 5.1.5, some polymer treatments/concentrations were selected and two types of salt crystallization tests were carried out on Globigerina limestone samples, the first one involving crystallization cycles and the second one involving continuous capillary absorption and evaporation of a saline solution. The results lead to the following conclusions:

- the TA treatment caused an unacceptable color change in the stone, so it was discarded;
- the polymeric solutions were absorbed to a large extent by the stone samples, but the polymers that deposited on pore walls caused no significant mass increase or pore blocking effect in Globigerina limestone, therefore not altering its wetting properties and water evaporation rate;

- the two salt crystallization tests gave very different results, due to their different mechanism of salt damage and severity. Cycles of soaking in a saturated $\mathrm{Na}_{2} \mathrm{SO}_{4}$ solution followed by drying for some hours in air at low relative humidity led to severe damage, which harshly deteriorated the cubic samples and made it difficult to assess the benefit provided by the treatments. However, a 
(a)

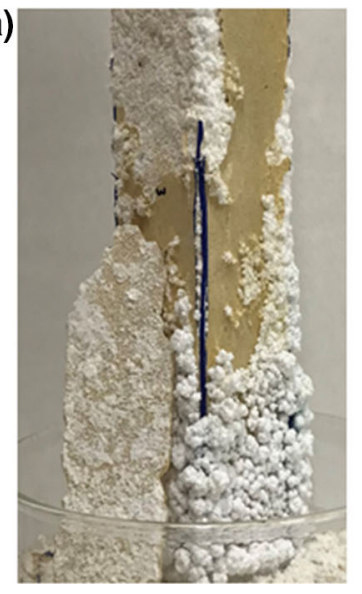

(b)

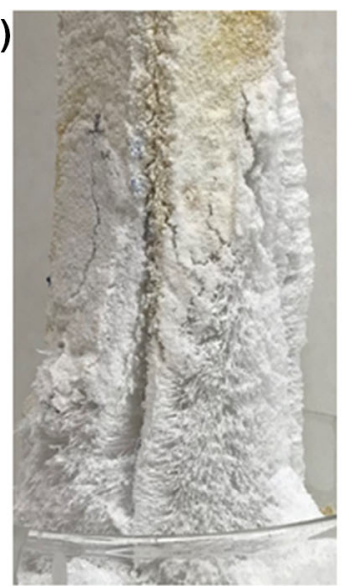

(c)

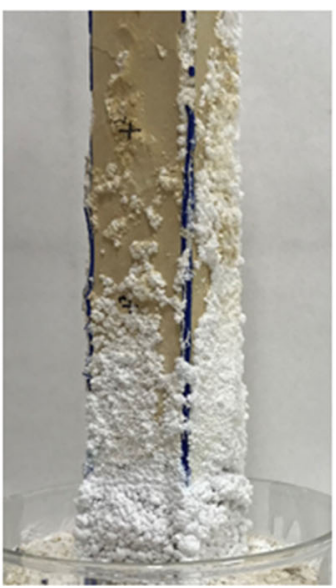

(d)

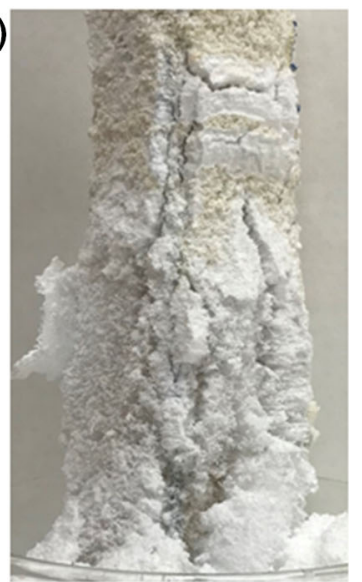

Fig. 12 Details of the specimens after 13 days of salt crystallization test: a GL-PAA; b GL-DAP-PAA; $\mathbf{c}$ GL-ALA; d GL-DAP-ALA

negative impact of PAA was assessed, and also ALA and CHIT worsened the salt resistance of the stone. A general benefit from the DAP pretreatment was assessed for all the treatments. The ALA and CHIT treatments improved the salt resistance of the stone when applied after DAP. The test under continuous capillary absorption of the saline solution is more realistic and clearly shows that the DAP treatment is beneficial for the stone, due to the strengthening effect of the new phases formed and possibly also to other mechanisms that need further investigation. The polymers caused some improvements of the stone resistance to salt damage, but their effectiveness was definitely more prominent if the DAP pretreatment was applied: this caused a reduction of the stone loss compared to the untreated stone equal to $-78 \%,-83 \%$ and $-93 \%$ for DAPPAA, DAP-ALA and DAP-CHIT, respectively. This confirms that the DAP-based treatment improves the adhesion of the polymer to the pore surface, prevents the dissolution of the substrate, increases the strength of the stone and promotes the formation of efflorescence rather that harmful subflorescence. However, the success of the different treatment is to be ascribed to different reasons, as PAA and ALA minimize the disjoining pressure, while CHIT is a crystallization inhibitor.

Further investigations are necessary to better understand the salt distribution inside the stone and the deterioration mechanisms actually occurring in the samples. In fact, the results found in the two salt crystallization tests seem influenced by multiple parameters: the contact angles of the polymers-solution (all hydrophilic, but slightly different); the promoting or inhibiting effect of the coatings on salt nucleation (promoting the formation of subflorescence or efflorescence); the variation of roughness induced by the coatings on the pore wall; the degree of coverage provided by the polymers over the pore surface; the distribution of the polymers in the pores of different size; the role of the $\mathrm{CaP}$ phases in the salt crystallization resistance of stone. Moreover, it should be considered that the mineralogy and microstructure of the stone are very important for the performance of the treatment. Tests performed on Indiana limestone (nearly pure calcite and very homogeneous) [21] and calcarenite stone [55] suggested a good performance of PAA, so future work should include a variety of lithotypes.

Acknowledgements Department of Civil, Chemical, Environmental, and Materials Engineering (DICAM) of the University of Bologna is gratefully acknowledged for financially supporting Serena Andreotti through the Marco Polo scholarship for scientific training abroad. This research has also been funded by the Spanish Government (Grants CGL2015-70642-R, CGL2015-73103-EXP), the University of Granada ("Unidad Científica de Excelencia" UCE-PP2016-05), the Junta de Andalucía (P11-RNM-7550), and the research group RNM-179 of the Junta de Andalucía. The technician Mrs. Aurelia Ibáñez Velasco, Prof. Nicolás Velilla Sánchez and Prof. Giuseppe Cultrone, the researchers Dr. Fulvio di Lorenzo and Mr. Luis Monasterio Guillot of the Department of Mineralogy and Petrology of the University of Granada, the technician Dr. Fátima Linares Ordoñez of the Center of Scientific Instrumentation (CIC) of Granada, Dr. Alberto Fregni and the 
technician Mr. Paolo Carta of DICAM (University of Bologna) are gratefully acknowledged for collaboration.

\section{Compliance with ethical standards}

Conflict of interest The authors declare that they have no conflict of interest.

Open Access This article is distributed under the terms of the Creative Commons Attribution 4.0 International License (http:// creativecommons.org/licenses/by/4.0/), which permits unrestricted use, distribution, and reproduction in any medium, provided you give appropriate credit to the original author(s) and the source, provide a link to the Creative Commons license, and indicate if changes were made.

\section{References}

1. Scherer GW, Flatt R, Wheeler G (2001) Materials science reseach for the conservation of sculpture and monuments. MRS Bull 26:44-50

2. Steiger M, Asmussen S (2008) Crystallization of sodium sulfate phases in porous materials: the phase diagram $\mathrm{Na} 2 \mathrm{SO} 4-\mathrm{H} 2 \mathrm{O}$ and the generation of stress. Geochim Cosmochim Acta 72:4291-4306

3. Espinoza-Marzal RM, Scherer GW (2010) Advance in understanding damage by salt crystallization. Acc Chem Res 43(6):897-905

4. Saidov TA, Pel L, van der Heijden GHA (2015) Crystallization of sodium sulfate in porous media by drying at a constant temperature. Int J Heat Mass Transf 83:621-628

5. Lubelli B, Cnudde V, Diaz-Goncalves T, Franzoni E, van Hees RPJ, Ioannou I, Menendez B, Nunes C, Siedel H, Stefanidou M, Verges-Belmin V, Viles H (2018) Towards a more effective and reliable salt crystallization test for porous building materials: state of the art. Mater Struct 51:55

6. Scherer GW (2004) Stress from crystallization of salt. Cement Concreate Res 34:1613-1624

7. Espinosa RM, Franke L, Deckelmann G (2008) Model for the mechanical stress due to the salt crystallization in porous material. Constr Build Mater 22:1758-1773

8. Espinoza-Marzal RM, Scherer GW (2008) Crystallization of sodium sulfate salts in limestone. Environ Geol 56:605-621

9. Schiro M, Ruiz-Agudo E, Rodriguez-Navarro C (2012) Damage mechanisms of porous materials due to in-pore salt crystallization. Phys Rev Lett 109(265503):1-5

10. Scherer GW (2002) Factors affecting crystallization pressure. In: Proceedings of international RILEM TC 186-ISA workshop on internal sulfate attack and delayed ETtringite formation, 4-6 September 2002. Villars, Switzerland

11. Franzoni E (2014) Rising damp removal from historical masonries: a still open challenge. Constr Build Mater 54:123-136

12. Rodriguez-Navarro C, Benning LG (2013) Control of crystal nucleation and growth by additives. Elements 9:203-209
13. Rodriguez-Navarro C, Linares-Fernandez L, Doehne E, Sebastiàn-Pardo E (2002) Effects of ferrocyanide ions on $\mathrm{NaCl}$ crystallization in porous stone. J Cryst Growth 243:503-516

14. Ruiz-Agudo E, Putnis CV, Pel L, Rodriguez-Navarro C (2013) Template-assisted crystallization of sulfates onto calcite: implication for the prevention of salt damage. Cryst Growth Des 13:40-51

15. Ruiz-Agudo E, Martìn-Ramos JD, Rodriguez-Navarro C (2007) Mechanism and kinetics of dehydration of epsomite crystals formed in the presence of organic additives. J Phys Chem B 111:41-52

16. Ruiz-Agudo E, Rodriguez-Navarro C, Sebastián-Pardo E (2006) Sodium sulfate crystallization in the presence of phosphonates: implication in ornamental stone conservation. Cryst Growth Des 6(7):1575-1583

17. Lubelli B, Van Hees RPJ (2007) Effectiveness of crystallisation inhibitors in preventing salt damage in building materials. J Cult Heritage 8:223-234

18. Granneman SJC, Lubelli B, van Hees RPJ (2017) Mitigating salt damage in lime-based mortars with mixed-in crystallization modifiers. Potsdam: s.n., 2017. 4th International conference on salt weathering of buildings and stone sculptures (SWBSS 2017), pp 100-107

19. Gupta S, Terheiden KH, Pel L, Sawdy H (2012) Influence of ferrocyanide inhibitors on the transport nad crystallization process of sodium chloride in porous building materials. Cryst Growth Des 12(8):3888-3898

20. Flatt RJ (2002) Salt damage in porous materials:how high supersaturations are generated. J Cryst Growth 242:435-454

21. Houck J and Scherer GW (2006) Controlling stress from salt crystallization. In: Fracture and failure of natural building stones. Springer, pp 299-312

22. Gustafson L (1998) Polymer application in stone: an attempt to decrease deterioration due to salt crystallization. Senior thesis, Department of Chemical Engineering, Princeton University

23. Andreotti S, Franzoni E, Degli Esposti M, Fabbri P (2018) Poly(hydroxyalkanoate)s-based hydrophobic coatings for the protection of stone in cultural heritage. Materials. https://doi.org/10.3390/ma11010165

24. Derluyn H, Saidov TA, Espinosa-Marzal RM, Pel L, Scherer GW (2011) Sodium sulfate heptahydrate I: the growth of single crystal. J Cryst Growth 329(1):44-51

25. Rodriguez-Navarro C, Doehne E (1999) Salt weathering: influence of evaporation rate, supersaturation and crystallization pattern. Earth Surf Proc Land 24:191-209

26. Graziani G, Sassoni E, Franzoni E, Scherer GW (2016) Hydroxyapatite coatings for marble protection: optimization of calcite covering and acid resistance. Appl Surf Sci 368:241-257

27. Naidu S, Blair J, Scherer GW (2016) Acid-resistent coatings on marble. J Am Ceram Soc 99(10):3421-3428

28. Sassoni E, Graziani G, Franzoni E (2016) An innovative phosphate-based consolidant for limestone. Part 1: Effectiveness and compatibility in comparison with ethyl silicate. Constr Build Mater 102:918-930

29. Sassoni E, Graziani G, Franzoni E (2016) An innovative phosphate-based consolidant for limestone. Part 2: 
Durability in comparison with ethyl silicate. Constr Build Mater 102:931-942

30. Sassoni E, Graziani G, Franzoni E (2015) Repair of sugaring marble by ammonium phosphate comparison with ethyl silicate and ammonium oxalate and pilot pplication to historic artifact. Mater Des 88:1145-1157

31. Sassoni E, Naidu S, Scherer GW (2011) The use of hydroxyapatite as a new inorganic consolidant for damaged. J Cult Heritage 12:346-355

32. Sassoni E (2018) Hydroxyapatite and other calcium phosphate for the conservation of cultural heritage: a review. Materials 11:557

33. Stoica R, Somoghi R, Doncea SM, Ion RM (2017) Preparation of alginate-chitosan polyelectrolyte complexes for encapsulation of natural polyphenols. Optoelectron Adv Mater Rapid Commun 11(1-2):113-118

34. Matsumoto Y, Ishii D, Iwata T (2017) Synthesis and characterization of alginic acid ester derivatives. Carbohydr Polym 171:229-235

35. Halim ALA, Kamari A, Philip E (2018) Chitosan, gelatin and methylcellulose films incorporated with tannic acid for food packaging. Int $\mathrm{J}$ Biol Macromol 120(Part A):1119-1126

36. Xu W, Han EH, Wang Z (2019) Effect of tannic acid on corrosion behavior of carbon steel in $\mathrm{NaCl}$ solution. J Mater Sci Amp Technol 35(1):64-75

37. Morse JW, Arvidson RS, Lüttge A (2007) Calcium carbonate formation and dissolution. Chem Rev 107:342-381

38. de Oliveira Arias JL, Scheneider A, Batista Andrade JA, Alves Vieira A, Caldas S, Primel EG (2018) Chitosan from shrimp shells: a renewable sorbent applied to the clean-up step of the QuEChERS method in order to determine multiresidues of veterinary drugs in different types of milk. Food Chem 240:1243-1253

39. Muxika A, Etxabide A, Uranga J, Guerrero P, de la Caba K (2017) Chitosan as a bioactive polymer: processing, properties and applications. Int $\mathrm{J}$ Biol Macromol Part 2:1358-1368

40. Diaz-Dosque M, Aranda P, Darder M, Retuert J, YazdaniPedram M, Arias JL, Ruiz-Hitzky E (2008) Use of biopolymers as oriented supports for the stabilization of different polymorphs of biomineralized calcium carbonate with complex shape. J Cryst Growth 310:5331-5340

41. Wheeler G, Mèndez-Vivar J, Goins ES, Fleming SA, Brinker, CJ (2001) Evaluation of alkoxylane coupling agents in the consolidation of limestone. In: 9th International congress on deterioration and conservation of stone, Venice, 2001
42. Possenti E, Colombo C, Bersani D, Bertasa M, Botteon A, Conti C, Lottici PP, Realini M (2016) New insight on the interaction of diammonium hydrogen phosphate conservation treatment with carbonatic substrates: a multi-analytical approach. Microchem J 127:79-86

43. EN 12370 (1999) Natural stone test methods. Determination of resistance to salt crystallization

44. Goudie AS (1986) Laboratory simulation of 'the wick effect' in salt weathering of rock. Earth Surf Proc Land 11(3):275-285

45. Cody RD (1990) Organo-crystalline interactions in evaporites systems: the effect of crystallization inhibition. J Sediment Petrol 61(5):704-715

46. Wu J, Zhong F, Li Y, Shoemaker CF, Xia W (2013) Preparation and characterization of pullulan-chitosan and pullulan-carboxymethyl chitosan blended films. Food Hydrocolloids 30(1):82-91

47. Tiraferri A, Maroni P, Caro Rodríguez D, Borkovec M (2014) Mechanism of chitosan adsorption on silica from aqueous solutions. Langmuir 30:4980-4988

48. Perry TD IV, Duckworth OW, McNamara CJ, Martin ST, Mitchell R (2004) Effects of the biologically produced polymer alginic acid on macroscopic and microscopic calcite dissolution rates. Environ Sci Technol 38(11):3040-3046

49. Flatt RJ, Caruso F, Sanchez AMA, Scherer GW (2014) Chemomechanics of salt damage in stone. Nat Commun 5:4823

50. Rodriguez-Navarro C, Doehne E, Sebastian E (2000) How does sodium sulfate crystallize? Implication for the decay and testing of building materials. Cem Concr Res 30:1527-1534

51. Graziani G, Sassoni E, Faranzoni E (2015) Consolidation of porous carbonate stones by an innovative phosphate treatment: mechanical strengthening and physical-microstructural compatibility in comparison with TEOS-based treatments. Heritage Sci 3(1):1-6

52. Scherer GW, Wheeler G (2009) Silicate consolidants for stone. Key Eng Mater 391:1-25

53. Scherer GW (1990) Theory of drying. J Am Ceram Soc 73(1):3-14

54. Doehne EF, Price CA (2010) Stone conservation: an overview of current research. Getty Publications, Los Angeles

55. Ruiz-Agudo E (2007) Prevención del daño debido a la cristalización de sales en el patrimonio histórico construido mediante el uso de inhibidores de la cristalización. Ph.D. thesis, 2007, University of Granada 